\title{
$1 \quad$ Hybrid histidine kinase BinK represses Vibrio fischeri biofilm signaling at multiple 2 developmental stages
}

Denise A. Ludvik ${ }^{1,2}$, Katherine M. Bultman ${ }^{1,3}$, and Mark J. Mandel ${ }^{1,3, *}$

${ }^{1}$ Department of Medical Microbiology and Immunology, University of Wisconsin-Madison, 7 Madison, WI USA

${ }^{2}$ Department of Microbiology-Immunology, Northwestern University Feinberg School of 10 Medicine, Chicago, IL USA

${ }^{3}$ Microbiology Doctoral Training Program, University of Wisconsin-Madison, Madison, WI USA

Short title: Antagonistic regulation by V. fischeri RscS and BinK

Keywords: biofilms, phosphorelay, two-component systems, symbiosis, Vibrio fischeri, Aliivibrio

18 fischeri

* Correspondence to:

24 University of Wisconsin-Madison

25 Department of Medical Microbiology and Immunology

261550 Linden Drive

27 Madison, WI 53706

28 Phone: (608) 261-1170

29 Fax: (608) 262-8418

30 Email: mmandel@wisc.edu

31

32

33

34 


\section{ABSTRACT}

The symbiosis between the Hawaiian bobtail squid, Euprymna scolopes, and its exclusive lightorgan symbiont, Vibrio fischeri, provides a natural system in which to study host-microbe specificity and gene regulation during the establishment of a mutually-beneficial symbiosis. Colonization of the host relies on bacterial biofilm-like aggregation in the squid mucus field. Symbiotic biofilm formation is controlled by a two-component signaling (TCS) system consisting of regulators RscS-SypF-SypG, which together direct transcription of the Syp symbiotic polysaccharide. TCS systems are broadly important for bacteria to sense environmental cues

43 and then direct changes in behavior. Previously, we identified hybrid histidine kinase BinK as a

44 strong negative regulator of $V$. fischeri biofilm regulation, and here we further explore the

45 function of BinK. To inhibit biofilm formation, BinK requires the predicted phosphorylation sites

46 in both the histidine kinase (H362) and receiver (D794) domains. Furthermore, we show that

47 RscS is not essential for host colonization when binK is deleted from strain ES114, and imaging

48 of aggregate size revealed no benefit to the presence of RscS in a background lacking BinK.

49 Strains lacking RscS still suffered in competition. Finally, we show that BinK functions to inhibit

50 biofilm gene expression in the light organ crypts, providing evidence for biofilm gene regulation

51 at later stages of host colonization. Overall, this study provides direct evidence for opposing

52 activities of RscS and BinK and yields novel insights into biofilm regulation during the maturation

53 of a beneficial symbiosis.

\section{IMPORTANCE}

Bacteria are often in a biofilm state, and transitions between planktonic and biofilm

57 lifestyles are important for pathogenic, beneficial, and environmental microbes. The critical

58 nature of biofilm formation during Vibrio fischeri colonization of the Hawaiian bobtail squid light

59 organ provides an opportunity to study development of this process in vivo using a combination

60 of genetic and imaging approaches. The current work refines the signaling circuitry of the biofilm 
61 pathway in $V$. fischeri, provides evidence that biofilm regulatory changes occur in the host, and

62 identifies BinK as one of the regulators of that process. This study provides information about

63 how bacteria regulate biofilm gene expression in an intact animal host.

\section{INTRODUCTION}

Animals are host to microbial partners that perform essential functions, including promoting tissue and immune development, nutrient acquisition, and defense $(1,2)$. In many cases, the hosts emerge aposymbiotic (i.e., lacking their symbiont) and must then recruit and retain the correct symbiotic microbes from the environment. On the microbial side, these horizontally-acquired symbionts often navigate multiple distinct lifestyles, including a free-living environmental stage and a distinct host-associated phase (3). To understand how reproducible symbiotic colonization occurs against this backdrop of distinct microbial life stages, we can use a model system in which a host organ is colonized by only a single bacterial partner. Here, we focus on marine Vibrio fischeri and their colonization of the light organ of the Hawaiian bobtail squid, Euprymna scolopes $(4,5)$. V. fischeri gains exclusive access to the squid's light organ niche and creates luminescence that the squid manipulates as a counter-illumination camouflage strategy $(6,7)$. Within hours of the aposymbiotic squid hatching, $V$. fischeri colonize the light organ $(8,9)$. In addition to the binary nature of the symbiosis and the ability to rear both partners separately, the amenability of $V$. fischeri to sophisticated genetic manipulation and the power to image at the direct site of infection provides a powerful tool box to study how genes

81 and their products influence bacterial colonization.

83 squid host $(3,10-15)$. During the establishment of the symbiosis, squid recruit $V$. fischeri by

84 pumping seawater through the mantle cavity and over the light organ. Biofilm formation is

85 required for $V$. fischeri to aggregate in the host mucus, and $V$. fischeri mutants unable to 86 synthesize biofilm are unable to colonize the squid $(10,11)$. The polysaccharide component of 
87 the biofilm is the symbiosis polysaccharide (Syp), whose production is encoded by the 18-gene syp locus on the $V$. fischeri second chromosome (11). Expression of this locus is controlled by a two-component phosphorelay (Figure 1A). In strain ES114, the current model posits that hybrid sensor kinase RscS autophosphorylates at residue H412 in its dimerization and histidine phosphotransferase (DHp) domain and then relays the phosphoryl group to D709 in its receiver domain (REC) (16). The phosphoryl group is then relayed to residue $\mathrm{H} 705$ in the histidine phosphotransfer (HPt) domain of a distinct hybrid sensor kinase, SypF $(17,18)$. SypF then phosphorylates D53 in the REC domain of response regulator SypG $(17,19)$. Phospho-SypG acts as a $\sigma^{54}$-dependent enhancer binding protein to promote transcription of the syp locus (11, 20). SypF has additional effects, including regulating the activity of serine kinase/phosphatase SypE to inactivate/activate its target SypA, which influences Syp biofilm formation downstream of syp transcription (21).

Previously, we identified the biofilm regulator, BinK, as a strong inhibitor of symbiotic biofilm formation (22). BinK was identified in an insertion sequencing screen where a mutant library of $V$. fischeri was analyzed before and after colonization of squid hatchlings to find genes that influenced colonization (23). Mutants of binK were overrepresented in the output pool compared to the input, suggesting that deletion of binK confers an advantage during the

104 colonization process. Upon further study, it was determined that deletion of binK confers a 105 competitive advantage against the wild-type strain during squid colonization, and the mutant

106 forms larger aggregates on the surface of the squid light organ (22). Overexpressing BinK leads

107 to a substantial reduction in symbiotic biofilm formation and prohibits bacteria from colonizing

108 the host. BinK, which is conserved across $V$. fischeri strains, was also identified to be an

109 important colonization regulator in a squid colonization experimental evolution study (14).

110 Natural $V$. fischeri fish and seawater isolates that were experimentally evolved to colonize squid 111 were able to do so as a result of spontaneous mutations in binK (14). Strain ES114 does not 112 form robust biofilms outside of the squid. However, we can use culture-based assays with an 
113 RscS-overexpressing allele (termed, $r s c S^{*}$ ) that approximates in vivo biofilm phenotypes to

114 study BinK function, and with those approaches we demonstrated that deletion of binK can lead

115 to wrinkled colony formation, higher transcription of the syp locus, and higher production of the

116 Syp exopolysaccharide (22). Overexpressing sypG is epistatic to inhibitory signaling from

117 overexpressing binK (22). The $\Delta$ binK strain is significantly derepressed for biofilm formation and

118 in that background, calcium stimulates colony biofilm formation without the need for induction by

$119 r s c S^{*}$ alleles (24). The calcium induction system led to the discovery of biofilm regulator HahK,

120 which influences biofilm development in response to host nitric oxide $(24,25)$.

Given the prominence of BinK as a strong negative regulator of biofilm across various $V$.

122 fischeri natural isolates, here we pursued multiple questions regarding its function during

symbiosis. First, while BinK has the predicted structure of a hybrid histidine kinase, we asked

whether it requires its putative phosphorylation sites for function. Second, given the strong

phenotypes of BinK, we asked whether canonical squid isolate ES114 would be capable of

colonizing squid in the absence of the positive regulator RscS if the negative regulator BinK was

127 also removed. We found that RscS was dispensable for colonization in the absence of BinK,

128 and this result enabled us to investigate the relative role of each protein during symbiotic

129 colonization. Third, using direct imaging of a fluorescent syp transcriptional reporter, we asked

130 whether symbiosis polysaccharide gene expression is regulated in the host by comparing

131 regulation at two distinct time points (and therefore, distinct sites with the host) and by

132 comparing both wild type and various mutant strains. Overall, this work provides an intriguing

133 look into how biofilm signaling is regulated when a symbiotic microbe encounters its animal

134 host.

135

136 RESULTS

137 BinK requires its conserved two-component histidine and aspartate for function 
We identified BinK as an orphan hybrid histidine kinase that inhibits biofilm formation and is a negative regulator of squid colonization (22). Protein domain prediction indicated that BinK has the conserved dimerization and histidine phosphotransferase (DHp) domain and

141 catalytic (CA) domain typical of a two-component sensor kinase, and it also contains an

142 additional receiver (REC) domain making it a hybrid sensor kinase (Figure 1B) (26-29). His362

143 in the DHp domain and Asp794 in the REC domain are the predicted sites for phosphorylation in

144 BinK (Figure 1C) (22). Phosphotransfer through such sites is typically required for signaling by

145 sensor kinases, but there are examples where this is not the case $(17,30,31)$. Therefore, we

146 first asked whether His362 and Asp794 are necessary for BinK function.

To assess the function of individual alleles, we conducted colony biofilm assays. We

148 started with a $\Delta$ binK strain and then introduced the binK gene (including 300 bp of upstream

149 and downstream sequence) into the neutral chromosomal atfTn 7 site (Figure 2A). This

150 approach enabled us to test the wild-type and mutant alleles in comparable isogenic

151 backgrounds. The strain background also has an allele to induce biofilm formation under culture

152 conditions through the overexpression of RscS. This allele, termed $r s c S^{*}$ is carried on the

153 chromosome at the native rscS locus (Figure 2A) (32). In this background, deletion of binK

154 results in a wrinkled colony morphology when grown at $28^{\circ} \mathrm{C}$, while a strain with a functional

155 binK has a smooth colony morphology (22). To test whether the His362 and/or Asp794 are

156 required for BinK function, we constructed $\mathrm{H} 362 \mathrm{Q}$ and D794A mutations, which have been

157 shown to mimic the unphosphorylated state when similarly introduced into homologous domains

$158(16,33)$. In an otherwise $\Delta$ binK background, mutation in either individual residue or in both

159 residues in the same protein resulted in a non-functional BinK (Figure 2B). We next asked

160 whether a predicted phosphomimetic allele of the REC domain D794E is functional. This allele

161 was constructed and unable to complement the lack of BinK in the $r s c S^{*}$ biofilm induction model

162 (Figure 2B). Using western blot analysis with a polyclonal antibody raised against a BinK

163 cytoplasmic epitope, we demonstrated that the mutant proteins are expressed to levels 
comparable to that of the wild-type BinK (Figure 2C). Together, these results provide genetic evidence that phosphorylation of BinK residues is required for its function. Given that we did not observe complementation with either the D794A that is predicted to be non-phosphorylatable or with the putative phosphomimetic D794E allele, we expect that phosphoryl groups at this residue are transferred to (or from) a downstream signaling partner, and that this signaling is required for BinK to inhibit biofilm formation.

\section{BinK merodiploid analysis reveals a dominant negative phenotype for the D794A allele}

173 nonfunctional. Given that histidine kinases typically operate as homodimers, we next inquired whether the BinK(H362Q) or BinK(D794A) had any effect when expressed in a cell that also expressed wild-type BinK protein. We continued to express the test alleles from the attTn7 site, but now did so in a strain expressing wild-type binK from the native locus. In the wrinkled colony assay, the nonfunctional $\mathrm{H} 362 \mathrm{Q}$ allele was recessive to the wild-type allele as expected, but the D794A allele exhibited a dominant negative phenotype, displaying a lack of biofilm inhibition even in the presence of the wild-type allele (Figure 2B). A similar dominance was observed for the D794A allele even if the H362Q mutation was introduced on the same polypeptide, a wild-type copy of BinK to inhibit biofilm formation. was similarly nonfunctional as the D794A allele when expressed as the only BinK allele in the cell. Merodiploid analysis revealed, however, that the D794E allele did not interfere with BinK

187 activity in trans (Figure 2B). This was the case whether it was the only mutation in binK or in the 188 context of a double binK(H362Q, D794E) allele (Figure 2B). Therefore, inactivation of the REC 189 domain does not correlate directly with the dominant interfering phenotype. However, it may be 
the case that an unphosphorylated D794 (and the D794A allele that cannot be phosphorylated)

191 leads to inhibition of BinK activity, whereas phosphorylated D794 (mimicked by the D794E 192 allele) does not.

Sensor kinases can perform both phosphatase and kinase activities (34). To ask

194 whether BinK kinase or phosphatase activity is used for biofilm inhibition, we created point

195 mutations in the DHp domain that are predicted to differentially affect kinase versus

196 phosphatase activities of the protein. BinK contains a conserved ExxT motif immediately after

197 the conserved His362 residue (Figure 1C). This region of the $\mathrm{H}$-box (i.e., the conserved

198 phosphoryl group-binding His and surrounding region) is important for coordinating the

199 phosphotransfer reactions in two-component proteins (35). In BinK we constructed E363A,

200 T366Q, and T366A mutations that are predicted to eliminate kinase activity, reduce

201 phosphatase activity, and eliminate phosphatase activity (with possible effects on autokinase

202 activity), respectively (35-41). Colony biofilm assays revealed nonfunctional BinK in each case

203 (Figure S1). This result further supports a role for phosphotransfer through BinK in its functional

204 role.

205

\section{Single-copy phosphomimetic SypG is epistatic to BinK overexpression}

As an orphan histidine kinase, BinK has no known paired response regulator. In a

208 previous study, we demonstrated that a separate RscS-dependent pathway that relies on

209 signaling through SypE was insensitive to BinK activity (22). Therefore, we can proceed to study

210 BinK signaling architecture in a $\triangle s y p E$ sypF2 mutant background to isolate the core biofilm

211 phosphorelay. Note that in this strain background, wrinkled colony formation is observed upon

212 overexpression of SypG (without the requirement for $\left.r s c S^{*}\right)(18,42)$. In our previous study, we

213 demonstrated that overexpression of SypG led the cell to be insensitive to overexpression of

214 BinK in a wrinkled colony assay (22). This result suggested that SypG was epistatic to BinK. To

215 further probe the genetic relationship between BinK and SypG, we constructed a 
216 phosphomimetic SypG allele at the native sypG locus. Hussa et al. demonstrated that a plasmid

217 containing the SypG(D53E) allele conferred increased syp transcription and wrinkled colony

218 formation in a $\triangle s y p E$ sypF2 strain (18). We introduced the same amino acid change into

219 chromosomal sypG within the $\triangle$ sypE sypF2 genetic background. We proceeded to determine

220 that overexpression of BinK does not reduce the colony biofilm produced in the $\Delta$ sypE sypF2

221 sypG(D53E) background (Figure S2). Therefore, this experiment supports and extends our

222 previous work and provides strong evidence that BinK acts upstream of SypG in the control of

223 syp transcription and biofilm development. We proceeded then to examine the relative impacts

224 of RscS and BinK on colonization phenotypes in vivo.

225

\section{RscS is not required for aggregation or squid colonization in a strain lacking BinK}

In strain ES114, the positive regulator RscS and the negative regulator BinK both exert

strong impacts on colonization and both act through the response regulator SypG. We therefore

considered models in which RscS and BinK exert opposing influence on syp gene transcription

during squid colonization. Deletion of rscS alone leads to severe in vivo biofilm and colonization

whether removal of both regulators--RscS and BinK--would enable the bacteria to colonize the

234 host. An examination of experiments in diverse $V$. fischeri strains provides some insight into this

235 question. Strains can improve their ability to colonize squid in the laboratory by mutation of binK,

236 and this includes strain MJ11 that naturally lacks RscS $(14,22)$. The same MJ11 strain can

237 colonize squid robustly if RscS from squid symbiont ES114 is introduced (13). Together, these

238 results support our model that RscS and BinK could exhibit opposing activities, but we remained

239 uncertain as to what we would observe in native squid symbiont ES114. If RscS is mainly

240 required to counteract the negative regulation of BinK, then elimination of both regulators should

241 allow the bacteria to colonize the squid host. However, if RscS is required to transduce a 
242 specific signal from the host, then we predict that elimination of both regulators would not allow

243 for colonization.

244 To test these models, we conducted single-strain colonization assays. As has been

245 shown previously, a $\Delta r s c S$ mutant exhibits a significant colonization defect (Figure 3) (43). The

$246 \Delta$ binK mutant is known to exhibit a competitive advantage over wild-type (22), yet in single-

247 strain colonization displays similar bacterial yields and luminescence (Figure 3). The $\Delta b i n K$

$248 \Delta r s c S$ double mutant strain was able to colonize up to levels indistinguishable from the wild-type

249 strain (Figure 3). This result therefore supports the model that in ES114 BinK and RscS

250 antagonize each others' activity, and that in the absence of the negative regulator BinK, the

251 positive regulator RscS is no longer required for single-strain colonization.

252 The above result was surprising in that we identified a condition in which RscS,

253 discovered twenty years ago as a strong colonization factor (43), was no longer required for

254 squid colonization in strain ES114. This prompted us to ask whether the key symbiotic behavior

255 regulated by RscS--in vivo aggregate formation--occurs in the $\Delta$ binK $\Delta r s c S$ background. For this

256 experiment, we introduced a plasmid that constitutively expresses GFP into the colonizing

257 strains from Figure 3, and we asked whether these strains form biofilm aggregates in the squid

258 mucus field. Direct visualization of the bacterial cells revealed the presence of biofilm

259 aggregates in the host for the $\Delta$ binK $\Delta r s c S$ cells (Figure 4A). Notably, the size of these

260 aggregates were comparable to those formed by $\Delta$ binK single mutant cells, which were larger

261 than the aggregates formed by wild-type $V$. fischeri (Figure 4A,B). This result therefore reveals

262 that RscS is not required for aggregate formation in a background lacking BinK, and RscS does

263 not contribute to aggregate size in this background.

264 The above results prompted us to ask whether RscS performs any detectable function in 265 a strain lacking BinK. We employed a sensitive competition assay to ask whether strains lacking

266 RscS exhibit a defect upon co-inoculation. In a competitive colonization assay in which the 
$\Delta$ binK $\Delta r s c S$ strain was co-inoculated with a LacZ-expressing $\Delta$ binK single mutant, the strain lacking RscS exhibited an approximately 100-fold defect in the competition (Figure 5).

\section{In the absence of BinK, syp transcription in vitro does not require RscS}

Recent work demonstrated that in a strain lacking BinK, RscS is not required for colony

272 biofilm formation when the symbiotic biofilm is induced with an additional $10 \mathrm{mM}$ calcium in the

273 medium (LBS-Ca) (24). We therefore examined a sypA'-gfp transcriptional reporter for cells

274 grown on LBS-Ca agar, in strains that lack BinK, RscS, or both regulators. We determined that

275 GFP activity from the reporter is induced in the $\Delta$ binK background, and the presence or

276 absence of $r s c S$ in this background did not impact syp expression (Figure 6A,C). Similarly, the

277 wrinkled colony biofilm phenotype is observed in both the $\Delta$ binK and $\Delta$ binK $\Delta r s c S$ strains. Next,

278 we examined the same reporter when the cells were grown on rich medium without the

279 additional calcium (LBS). On LBS agar, the overall induction is lower than on LBS-Ca and

280 strains do not wrinkle. However, we still detect induction of the reporter in the $\Delta$ binK strain

281 compared to the WT parent. The induction is unaffected by the absence of $r s c S$ from this

282 background (Figure 6B,C). In summary, we can readily detect syp gene transcription in the

$283 \Delta$ binK background when grown on different solid media, and this induction is independent of

284 RscS.

\section{BinK represses syp transcription in the squid crypts}

We next examined expression of the sypA'-gfp ${ }^{+}$transcriptional reporter in $V$. fischeri

288 cells that had aggregated in the host mucus (3-4 hpi). The results in Figure 7A,C reveal

289 indistinguishable overall levels of GFP activity in WT, $\Delta b i n K$, and $\Delta b i n K \Delta r s c S$ cells in the

290 aggregates of each animal examined. We note some limitations to these data. Given that cells

291 spend a short period of time in the aggregate stage--on the order of $1-2 \mathrm{~h}$--it is unclear whether

292 the reporter is revealing the steady state transcription levels from the aggregate or whether this 
293 information integrates time prior to the aggregation stage (growth in liquid media and in

294 seawater). Nonetheless, we present these data for two reasons. First, any physiological

295 response that uses transcription to regulate symbiosis would be subject to similar constraints.

296 Second, the similarity of the data points provides a useful control for the data in the crypts that

297 will be described below. Even with these caveats, we can conclude that the absence of RscS

298 does not diminish the median level of $\operatorname{syp} A$ transcription in the $\Delta$ binK background. We note that

299 there was more heterogeneous sypA'-gfp ${ }^{+}$activity across the aggregate in wild type compared

300 to samples that lacked BinK (Figure 7A).

$301 \quad$ We proceeded to conduct a similar analysis of the transcriptional reporter in the light

302 organ crypts (48 hpi). At this point, we observed a notable difference between the $\Delta$ binK strain

303 and wild type, with substantially elevated sypA transcription in the cells lacking BinK (Figure

304 7B,D). The absence of RscS did not affect the sypA reporter. From this imaging, we conclude

305 that a normal function of BinK is to repress syp transcription in the crypts.

306

DISCUSSION

By studying the $V$. fischeri-squid symbiosis model, we have refined our understanding of how bacterial biofilm signaling is regulated at the initiation of bacterial colonization. This study provides evidence that BinK acts as a hybrid histidine kinase, defines novel biofilm regulation in

311 the host, describes a role for BinK in that regulation, and reveals that the key ES114

312 colonization factor RscS is dispensable in the absence of BinK. These major conclusions are 313 discussed in detail below.

BinK acts as a hybrid histidine kinase. In our previous study, we identified BinK as a

315 putative hybrid histidine kinase based on its predicted domain structure containing CA, DHp,

316 and REC domains (Figure 1) (22). Furthermore, experimental evolution studies to improve

317 squid colonization of other $V$. fischeri strains revealed spontaneous binK point mutations in its

318 CA and HAMP domains that approximated the phenotypes of $\Delta b i n K$ strains, suggesting key 
roles for these domains in BinK function (14). In this work, we used a combination of targeted mutants with a newly-developed anti-BinK peptide antibody to demonstrate that mutagenesis of predicted phosphorylation sites creates BinK proteins that are nonfunctional.

In most cases, histidine kinases dimerize, and our results provide genetic support that

323 this occurs in the case of BinK. In particular, our finding that a BinK protein containing a REC

324 domain that is locked as non-phosphorylated with the D794A mutation is not only nonfunctional,

325 but is dominant negative as it interferes with signaling of a wild-type binK allele expressed in the

326 same cell. There are published cases in which one monomer's REC domain interacts with the

327 same monomer's DHp domain (in cis), and other cases in which it interacts with the partner

328 monomer's DHp domain (in trans) $(44,45)$. In both cases, however, dynamic movement of both

329 monomers is required across the dimer interface $(35,46)$. It seems likely that the BinK D794A

330 allele disrupts some aspect of this dynamic process that is still intact in heterodimers containing

331 the phosphomimetic D794E allele. Therefore, BinK REC domain phosphorylation may both

332 contribute to phosphoryl group flow and regulate the ability of BinK to interact in productive

333 dimers.

Our data support a model in which phosphoryl groups flow from/to a downstream signaling partner through the BinK REC domain. The lack of complementation of a $\Delta$ binK allele with either the binK(D794A) or binK(D794E) alleles provide support for this model, in spite of

337 differences in the merodiploid analysis described above. Additionally, the double binK(H362Q,

338 D794E) allele is nonfunctional but not disruptive in the presence of a wild-type allele, suggesting

339 that phosphoryl group flow can proceed in cis through a single BinK monomer even when

340 present in mixed dimers with the double mutant. We note that there are examples in the

341 literature where a REC domain regulates activity of the DHp domain and does not directly

342 transfer phosphoryl groups $(30,31,47)$. While this is possible for BinK, it seems unlikely given

343 the genetic results here. Future biochemical analysis of BinK phosphotransfer will be necessary

344 to further advance these studies. In particular, such analysis may enable asking whether BinK 
acts as a kinase or phosphatase when it inhibits biofilm formation. Without knowledge of the direct downstream partner of BinK, this question is difficult to access at present. acting to control the phosphorylation of SypG. Our results indicate that the BinK His and Asp residues are necessary for activity. Thus, we predict BinK acts indirectly on SypG through the

350 HPt domain in another regulator. Among known players, the HPt domain that has been shown

351 to mediate phosphorylation of SypG is that of SypF $(17,24)$, making SypF a likely candidate. It

352 is also possible that the relevant partner has yet to be identified. Genetic approaches to identify

353 and characterize relevant partners will provide insight into the pathway downstream of BinK.

RscS is dispensable for colonization in strain ES114 lacking BinK. We found that in strain ES114, rscS is not required for squid colonization in a $\Delta$ binK background. Strains lacking both regulators colonize to a level comparable to that of wild type, though we found through competitive colonization analysis that there still remains a role for RscS in this background

(Figures 3, 5). There are three major phylogenetic groups of $V$. fischeri (15). Relevant for this include fish symbionts such as MJ11, which cannot colonize squid unless they gain RscS or lose BinK $(13,14)$. Derived from this group is Group B, which includes strain ES114, which is

364 the focus of the present study. Squid symbionts in Group B typically encode both RscS and

365 BinK, and mutation of RscS leads to an inability to colonize the squid $(13,15)$. In this study, it 366 was found that when binK is deleted, strain ES114 no longer requires rscS for colonization

367 (Figure 3). This result mirrors a previous finding in Group C, which found that strains lacking

368 RscS (due to evolution) and also lacking BinK (due to directed mutation) could colonize squid

369 (14). Given the diversity of biofilm regulation across $V$. fischeri, this result was not expected and 370 highlights conserved aspects of regulation that are shared across much of the species (15). It 
371 therefore seems that one of the main functions of RscS is to antagonize BinK's negative

372 regulation of biofilm: without the negative regulator, the positive regulator is no longer absolutely

373 required for host colonization. From the evolutionary tree, we know that binK--which is found

374 throughout the species--predates the horizontal gene transfer event that enabled acquisition of

$375 r s c S$, which is only present in a derived group of $V$. fischeri $(13,15)$. Therefore, our work raises

376 the question of whether there are other factors that antagonize BinK activity in strains that

377 colonize squid independent of RscS (e.g., the Group C Mediterranean squid symbionts). It

378 seems likely that such activity would be sufficient to enable colonization, given that mutations in

379 binK facilitate colonization by strains that are otherwise unable to colonize well (14).

BinK is a key regulator across the symbiotic life cycle. In a previous study, we used

a fluorescent biofilm gene promoter fusion to examine gene expression in liquid medium (22). In this work, we expanded on that approach to examine expression of sypA'-gfp ${ }^{+}$on solid medium and in vivo during colonization. On solid agar, we observed high levels of reporter expression under conditions known to induce Syp biofilm formation (LBS-Calcium (24)). We observed a less dramatic yet significant induction on medium where the Syp biofilm is not visibly apparent (LBS), revealing the sensitivity of this reporter. Our results provide evidence for expression of the syp biofilm in the aggregates, when biofilm formation is known to be required for colonization. We also demonstrate that in the absence of BinK, there is expression of syp reporter in the crypts, which supports a role for BinK in repressing biofilm gene expression at this later stage in the wild type strain. Building on our observation above that RscS is

391 dispensable for colonization in strains lacking BinK, we observed similar levels of syp reporter 392 expression in $\Delta$ binK and $\Delta$ binK $\Delta r s c S$ strains. Our discovery that BinK functions to repress syp 393 expression in the crypts hints that BinK regulation may serve a role in the daily expulsion of

394 bacteria from squid at dawn. Little is known about how this process is regulated, yet it occurs 395 daily in the mature symbiosis for the duration of the host's lifetime. If this proves correct, it may 396 help to explain why binK genes are widely conserved in $V$. fischeri despite the mutant having a 
competitive advantage $(14,15,22)$. It seems likely that while the absence of BinK is beneficial

398 to enter the squid host, the absence of the regulator (and subsequent inappropriate biofilm

399 formation at later stages) may be detrimental to the daily homeostasis that is maintained long-

400 term in the squid. We also examined sypA'-gfp ${ }^{+}$reporter activity in biofilm aggregates. The

401 average expression level within aggregates was similar for wild type or $\Delta$ binK mutant cells, but

402 we observed greater heterogeneity in the expression in wild type. This suggests that in the

403 presence of BinK, there is more variability in biofilm expression, and this is worthy of further

404 study.

$405 \quad$ This work provides an exciting view into how biofilm gene expression is regulated in

406 vivo. We know that within a few hours, planktonic bacteria transition to a biofilm state in the host

407 mucus $(3,48)$. Despite a number of biofilm regulators being identified, how this process is

408 controlled at the host interface is not well understood. Our results provide evidence that this

409 regulation is dynamic over the course of colonization, as evidenced by the BinK-dependent

410 repression that occurs specifically in the crypts at 48 hpi but is not evident in the aggregates at

$4113-4 \mathrm{hpi}$. We propose that the interaction of BinK with host-derived compounds may lead to

412 downregulation of biofilm genes as bacteria transition from the biofilm aggregates during

413 initiation to cells in the crypts during the persistence stage. Finally, we observed similar sizes of

414 in vivo biofilm aggregates in the host in $\Delta b i n K$ and $\Delta b i n K \Delta r s c S$ strains, arguing that there is no

415 requirement for stimulation of biofilm through RscS to initiate a productive symbiosis. We

416 therefore posit that a key regulatory mechanism to control the planktonic-to-biofilm transition is

417 host inhibition of BinK.

418 In summary, this work provides novel insight into the function of hybrid histidine kinase

419 BinK, its relationship to RscS is regulating symbiotic biofilm formation, and the temporal control

420 of symbiotic biofilm gene expression. Future work will continue to examine the signaling

421 architecture downstream of BinK and host-derived molecules that may regulate BinK activity. 


\section{MATERIALS AND METHODS}

424 Bacterial Strains, Plasmids, and Media

$425 \quad$ V. fischeri and Escherichia coli strains used in this study are listed in Table 1. Plasmids used in

426 this study are listed in Table 2. V. fischeri strains were grown at $25^{\circ} \mathrm{C}$ or $28^{\circ} \mathrm{C}$ in Luria-Bertani 427 salt (LBS) medium (25 g Difco LB broth [BD], $10 \mathrm{~g} \mathrm{NaCl}$, and $50 \mathrm{~mL} 1 \mathrm{M}$ Tris buffer, pH 7.5, per

428 liter). E. coli strains, used for cloning and conjugation, were grown shaking at $37^{\circ} \mathrm{C}$ in Luria-

429 Bertani (LB) medium (25 g Difco LB broth [BD] per liter). Growth media were solidified with 1.5\% 430 agar (15 g Bacto agar (BD) per liter) as needed. When necessary, antibiotics were added to the 431 media at the following concentrations: erythromycin, $5 \mu \mathrm{g} / \mathrm{ml}$ for $V$. fischeri; kanamycin, 100

$432 \mu \mathrm{g} / \mathrm{ml}$ for $V$. fischeri and $50 \mu \mathrm{g} / \mathrm{ml}$ for $E$. coli; and chloramphenicol, $5 \mu \mathrm{g} / \mathrm{ml}$ for $V$. fischeri and 25 $433 \mu \mathrm{g} / \mathrm{ml}$ for E. coli. The E. coli strain $\pi 3813$ containing pKV496 is a thymidine auxotroph and was 434 grown in LB with $50 \mu \mathrm{g} / \mathrm{ml}$ kanamycin supplemented with $0.3 \mathrm{mM}$ thymidine $(49,50)$.

\section{DNA synthesis and sequencing}

437 Each of the primers listed in Table 3 was synthesized by Integrated DNA Technologies

438 (Coralville, IA). Full inserts from all cloned constructs were verified by Sanger DNA sequencing 439 at Northwestern University Feinberg School of Medicine Center for Genetic Medicine,

440 Functional Biosciences via UW-Madison, or the UW-Madison Biotechnology Center. Sequence

441 data were analyzed with SeqMan Pro (DNAStar software) and Benchling. For cloning and

442 sequencing PCR reactions, we used Q5 High-Fidelity DNA polymerase (NEB). For diagnostic

443 PCR, we used GoTaq polymerase (Promega).

\section{Construction of attTn 7::binK mutant alleles}

446 The previously generated pTn7-binK plasmid, which uses a mini-Tn 7 delivery vector backbone 447 (pEVS107), was purified and used as a template. Point mutations to the binK sequence on the 448 plasmid were designed using the NEBaseChanger tool and constructed with the Q5 site- 
directed mutagenesis kit (New England BioLabs, Inc.). The constructed plasmid was transformed into either electrocompetent or chemically competent $\mathrm{DH} 5 \alpha \lambda$ pir E. coli. The entire binK gene on the plasmid construct was sequenced (using pEVS107 F and R primers and binK

452 sequencing primers). BinK alleles generated in this manner were then introduced into $V$. fischeri

453 by tetraparental mating by mixing the pEVS104-containing helper, pUX-BF13-containing

454 transposase, pEVS107 mini-Tn7 vector containing donor, and the $V$. fischeri recipient (51). PCR

455 verification by amplifying around the att $\operatorname{Tn} 7$ site with primers $\operatorname{Tn} 7$ site $\mathrm{F}$ and $\mathrm{Tn} 7 \mathrm{site} \mathrm{R}$

456 confirmed transposon insertion at the att $\operatorname{Tn} 7$ site.

\section{Wrinkled Colony Assays}

459 Cultures were grown overnight and $8 \mu \mathrm{L}$ was spotted onto LBS plates or LBS-Calcium (10 mM

$460 \mathrm{CaCl}_{2}$ ). Plates were incubated at $25^{\circ} \mathrm{C}$ or $28^{\circ} \mathrm{C}$ for 48 hours and imaged using Leica M60

461 stereomicroscope with Leica Firecam software. For assays done with the pM1422 reporter,

462 plates were also imaged on a Zeiss Axio Zoom.v16 large-field fluorescent stereo microscope

463 and analyzed with Zen Blue software.

464

465

BinK peptide antibody creation and purification

466

ProSci (Poway, CA) analyzed the sequence of BinK and chose the peptide was synthesized by ProSci and used to inoculate rabbits. Serum was analyzed at specific checkpoints to assess antibody production. Final bleed serum was then purified in our

470 laboratory using a Proteus Protein A Mini Purification Starter Kit and yielded approximately 1 $471 \mathrm{mg} / \mathrm{mL}$ of the antibody. Purified antibody was diluted $1: 1 \mathrm{in} 50 \%$ glycerol, aliquoted into small 472 volumes, and stored at $-20^{\circ} \mathrm{C}$. Single aliquots were thawed and used for each blot. 
476 One milliliter of overnight culture was pelleted, washed, and lysed in $1 \%$ SDS. The volume of

477 SDS used to lyse the sample was adjusted based on the $\mathrm{OD}_{600}$ of the overnight culture to

478 standardize the concentration of total protein in the samples. The solution was then pelleted to

479 remove cell debris and the supernatant was mixed 1:1 with 2x Laemli sample buffer (Bio-Rad)

480 and beta-mercaptoethanol. Samples were heated at $95^{\circ} \mathrm{C}$ for 15 minutes and loaded onto a

481 10\% Bio-Rad Mini-PROTEAN TGX Precast Gel. The gel was then transferred to a PVDF

482 membrane and blocked overnight in 5\% non-fat milk. The purified anti-BinK-peptide antibody

483 was used as the primary antibody in a 1:100 dilution in $0.5 \%$ nonfat milk in 1X TBS-Tween20.

484 The secondary antibody was a 1:5,000 dilution of the Pierce goat anti-rabbit lgG $(\mathrm{H}+\mathrm{L}) \mathrm{HRP}-$

485 conjugate (Lot UK293475). Washes were done in 1X TBS-Tween20. Blots were developed

486 using the ThermoScientific SuperSignal West Dura Extended Duration Substrate and analyzed

487 using a Licor Odyssey Fc machine.

\section{Construction of sypG(D53E)}

490 Site-direction mutation of sypG was done using an allelic exchange approach modified from the

491 laboratory's gene deletion protocol (https://doi.org/10.5281/zenodo.1470836). In brief,

492 approximately 1.6-kb upstream sequence and 1.6-kb downstream sequence of the desired point

493 mutation site in sypG was amplified from ES114 genomic DNA using primers designed using

494 the NEB site-directed mutagenesis approach. These two fragments were then cloned into

495 pEVS79 (which had been linearized by primers MRH001 and MRH002) using isothermal

496 assembly (NEBuilder HiFi DNA assembly cloning kit) with the primer combinations listed in

497 Table 3. The reaction was transformed into E. coli with selection for transformants on LB-

498 chloramphenicol. PCR around the insertion using primers M13 For (-41) and M13 Rev (-48) was

499 used to confirm plasmid candidates. The resulting candidates were then confirmed by

500 sequencing and conjugated into the $V$. fischeri recipient (KV3299/MJM2536) by triparental 
501 mating with helper plasmid pEVS104, selecting for the chloramphenicol resistance of the

502 plasmid backbone. Single recombinants in V. fischeri were screened for maintaining

503 chloramphenicol resistance. To obtain double recombinants, single recombinants were then

504 grown without antibiotics and patched onto LBS and LBS-Cam to find isolates that lost the

505 antibiotic resistance cassette. These candidates were then verified with PCR and sequencing to

506 confirm loss of the cam cassette and mutation of sypG to sypG(D53E). Strain MJM2536

507 sypG(D53E) was saved as MJM3236.

\section{Construction of $\Delta r s c S$ and $\Delta$ binK $\Delta r s c S$ strains}

510 Deletion of $\operatorname{rsc} S$ was performed following the barcode-tagged gene deletion protocol from

511 Burgos et al. (52). In brief, the US homology arm was amplified using primers KMB_082 and

512 KMB_083 and the DS homology arm was amplified using primers KMB_086 and KMB_087.

513 Homology arms were fused to either side of a third fragment containing an erm cassette using

514 SOE-PCR. Mutagenic DNA was purified using the Qiagen PCR purification kit and transformed

515 into ES114 via transformation using pLostfoX-Kan (MJM1538) $(53,54)$. Mutant candidates were

516 selected using erythromycin and screened by PCR using primer pairs KMB_081/KMB_088,

517 KMB_081/HB8, and KMB_084/KMB_085. Insertion of the Erm-bar scar was confirmed by

518 Sanger sequencing using primers KMB_081, KMB_082, KMB_083, HB8, HB9, KMB_086,

519 KMB_087, KMB_088 and the barcode sequence recorded. The final bar-scar strain (MJM3903)

520 was constructed via a triparental mating with donor MJM3478 ( $\pi 3813 / p K V 496)$ (50) and helper

521 strain MJM534 (CC118 Apir/pEVS104) with MJM3775. Candidates were selected for using

522 kanamycin and screened by PCR using the primer pairs listed above. The deletion scar was

523 verified by Sanger sequencing using primers KMB_081, KMB_082, KMB_083, HB41, HB42,

524 KMB_086, KMB_087 and KMB_088.

$525 \quad$ To create the $\Delta$ binK $\Delta r s c S$ strain, a $\Delta$ binK strain with the pLostfoX-Kan plasmid

526 (MJM2252) was cultured for transformation (54). Donor DNA was 2.4 ug of genomic DNA from 
527 the $\Delta r s c S$ ::erm-bar strain that was purified using the Qiagen Blood and Tissue Kit. Transformed

528 cells were plated onto LBS containing erythromycin to select for transformants. Isolates were

529 then patched onto LBS containing kanamycin to ensure loss of the pLostfoX-Kan plasmid. PCR

530 was performed to ensure the strain was transformed with $\Delta r s c S:: e r m$-bar and maintained $\Delta$ binK

531 (primers DAT_011F BinK ext, DAT_012R BinK ext, KMB_081, KMB_088). The erm cassette

532 was then removed using a FLP recombinase as described with the $\Delta r s c S:: b a r$ strain above to

533 create the final $\Delta$ binK $\Delta r s c S:$ :bar strain (MJM4018).

535 Squid single strain colonizations

$536 V$. fischeri strains were grown overnight with aeration at $25^{\circ} \mathrm{C}$ in LBS. Overnight cultures were

537 diluted 1:80 in LBS and grown to an $\mathrm{OD}_{600}$ of approximately 0.3 . The $\mathrm{OD}_{600}$ was used to

538 normalize the amount of each strain used to inoculate E. scolopes hatchlings at concentrations

539 of approximately $6 \times 10^{3} \mathrm{CFU} / \mathrm{mL}$ in $40 \mathrm{~mL}$ seawater for 3 hours. Squid were then washed and

540 transferred to individual vials with $4 \mathrm{~mL}$ of bacteria-free filter-sterilized Instant Ocean (FSIO)

541 until approximately 48 hours post-inoculation (hpi) with a water change that occurred at 24 hpi.

542 At $48 \mathrm{hpi}$, squid were transferred to $1.5 \mathrm{~mL}$ microfuge tubes with $750 \mathrm{~mL}$ of water and each

543 animal's luminescence was measured using the Promega GloMax 20/20 luminometer.

544 CFU counts per light organ were conducted as we described previously: euthanized

545 squid were homogenized and plated, and colonies were counted to determine CFU per light

546 organ (55).

$547 \quad$ For crypt visualization, squid were anesthetized in $\mathrm{FSIO}$ with $2 \%$ ethanol. At this point,

548 hatchlings were either immediately dissected and imaged, or fixed in 4\% paraformaldehyde in

$5491 \mathrm{X}$ mPBS (50 mM phosphate buffer, $0.45 \mathrm{M} \mathrm{NaCl}, \mathrm{pH} 7.4$ ) for approximately 36 hours. Fixed

550 squid were thoroughly washed in $1 \mathrm{X}$ mPBS before being dissected and imaged. All images

551 were acquired on the Zeiss Axio Zoom.v16 large-field stereo microscope. The Zen Blue

552 software polygon tool was used to select regions of interest and measure fluorescence intensity. 


\section{Squid aggregation assays}

554 V. fischeri strains were grown overnight with aeration at $25^{\circ} \mathrm{C}$ in LBS. $40 \mathrm{~mL}$ of overnight culture

555 was used to inoculate E. scolopes hatchlings at concentrations of approximately $5.5 \times 10^{6}$

$556 \mathrm{CFU} / \mathrm{mL}$ in $40 \mathrm{~mL}$ for $3-4$ hours. Hatchlings were then anesthetized in $\mathrm{FSIO}$ with $2 \%$ ethanol. At

557 this point, hatchlings were either immediately dissected and imaged, or fixed in $4 \%$

558 paraformaldehyde in 1X mPBS (50 mM phosphate buffer, $0.45 \mathrm{M} \mathrm{NaCl}, \mathrm{pH} 7.4$ ) for

559 approximately 36 hours. Fixed squid were thoroughly washed in 1X mPBS before being

560 dissected and imaged. All images were acquired on the Zeiss Axio Zoom.v16 large-field

561 fluorescent stereo microscope. The Zen Blue software polygon tool was used to select regions

562 of interest and measure both area and fluorescence intensity

\section{Squid competition assays}

565 Strains were grown overnight with aeration at $25^{\circ} \mathrm{C}$ in LBS and LBS containing kanamycin to

566 maintain plasmid pVSV103. Strains with pVSV103 constitutively express LacZ ( $\beta$ -

567 galactosidase). Overnight cultures were diluted 1:80 in LBS and grown to an $\mathrm{OD}_{600}$ of

568 approximately 0.3 . Using optical density to normalize the strains, the two strains were mixed in a

569 1:1 ratio. This mixed culture was used to inoculate $E$. scolopes hatchlings at concentrations of

570 approximately $7.6 \times 10^{3}$ bacteria for 3 hours. Squid were then washed and transferred to $40 \mathrm{ml}$

571 of bacteria-free filter-sterilized Instant Ocean (FSIO) until approximately 48 hours post-

572 inoculation (water was changed at $24 \mathrm{~h}$ post-inoculation), at which point they were euthanized

573 by storage at $-80^{\circ} \mathrm{C}$. Each squid was homogenized and plated on LBS-Xgal, and the blue/white

574 colony ratios were used to score these competitions as described previously $(23,55)$. 


\section{Data analysis and graphing}

577 Data analysis was conducted using Python, including the pandas library. For fluorescence of

578 colonies, aggregates, and crypts, the mean GFP and mCherry for the region of interest and a

579 nearby background region was acquired using Zen Blue Software. The background for each

580 channel was subtracted from the region of interest. To normalize GFP to plasmid copy number,

581 GFP was divided by mCherry. This resulted in the reported mean GFP/mCherry reading for

582 each individual colony, aggregate, or crypt space. Graphpad Prism was used to construct

583 graphs and perform statistical analyses.

584

\section{ACKNOWLEDGMENTS}

586 We thank John F. Brooks II for contributing strains for this study and Karen L. Visick for helpful

587 comments on the manuscript. This work was funded by NIGMS grant R35 GM119627 to M.J.M.

588 Support for trainees was provided by NIGMS T32 GM008061 (D.A.L), T32 GM008349 (K.M.B.), 589 and an NSF Graduate Research Fellowship to K.M.B.

Table 1: Strains used in this study

\begin{tabular}{|l|l|l|}
\hline Strain & Genotype & Source or Reference(s) \\
\hline $\begin{array}{l}\text { V. fischeri } \\
\text { MJM1100 } \\
\text { ES114 }\end{array}$ & Natural isolate, squid light-organ & \\
\hline MJM1107 & MJM1100 pVSV102 & $(56,57)$ \\
\hline MJM1198 & MJM1100 rscS* & $(23)$ \\
\hline MJM1438 & MJM1100 pM1422 & $(32)$ \\
\hline MJM1538 & MJM1100 pLostfoX-Kan & JF Brooks II \\
\hline MJM1575 & MJM1100 pVSV103 & $(23)$ \\
\hline MJM2251 & MJM1100 $\Delta$ binK & $(22)$ \\
\hline MJM2252 & MJM2251 pLostfoX-Kan & $(22)$ \\
\hline
\end{tabular}




\begin{tabular}{|c|c|c|}
\hline MJM2255 & MJM1100 rscS* $\Delta$ binK & (22) \\
\hline MJM2265 & MJM2251 pVSV102 & (22) \\
\hline MJM2475 & MJM1198 atfTn7::binK & $(22)$ \\
\hline MJM2476 & MJM2255 atfTn 7::binK & (22) \\
\hline MJM2479 & MJM1198 attTn7::erm & (22) \\
\hline MJM2480 & MJM2255 attTn7::erm & (22) \\
\hline MJM2484 & MJM2255 atfTn 7::binK(H362Q) & JF Brooks II \\
\hline MJM2493 & MJM2251 pM1422 & JF Brooks II \\
\hline $\begin{array}{l}\text { MJM2536 = } \\
\text { KV3299 }\end{array}$ & ES114 $\Delta$ sypE sypF $F^{*}$ & $(18,42)$ \\
\hline MJM3210 & MJM1198 attTn7::binK(H362Q) & This study \\
\hline MJM3213 & MJM1198 attTn7::binK(D794A) & This study \\
\hline MJM3215 & MJM2255 attTn7::binK(D794A) & This study \\
\hline MJM3218 & MJM1198 attTn7::binK(H362Q,D794A) & This study \\
\hline MJM3220 & MJM2255 atfTn7::binK(H362Q,D794A) & This study \\
\hline MJM3221 & MJM2251 pVSV103 & This study \\
\hline MJM3236 & MJM2536 sypG(D53E) & This study \\
\hline MJM3251 & MJM1198 attTn7::binK(D794E) & This study \\
\hline MJM3252 & MJM2255 attTn7::binK(D794E) & This study \\
\hline MJM3256 & MJM1198 attTn7::binK(E366A) & This study \\
\hline MJM3257 & MJM2255 $\Delta$ binK attTn 7::binK(E363A) & This study \\
\hline MJM3775 & MJM1100 $\Delta r s c S:: e r m-b a r$ & This study \\
\hline MJM3903 & MJM1100 $\Delta r s c S:: b a r$ & This study \\
\hline MJM4017 & MJM1100 $\Delta$ binK $\Delta r s c S:: e r m$-bar & This study \\
\hline MJM4018 & MJM1100 $\Delta$ binK $\Delta r s c S:: b a r$ & This study \\
\hline MJM4071 & MJM4018 pVSV102 & This study \\
\hline MJM4240 & MJM3236 pVSV104 & This study \\
\hline MJM4241 & MJM3236 pBinK & This study \\
\hline MJM4242 & KV3299 pVSV104 & This study \\
\hline MJM4243 & KV3299 pBinK & This study \\
\hline MJM4251 & MJM1198 attTn7::binK(H362Q,D794E) & This study \\
\hline MJM4252 & MJM2255 attTn7::binK(H362Q,D794E) & This study \\
\hline
\end{tabular}


bioRxiv preprint doi: https://doi.org/10.1101/2021.03.29.437627; this version posted May 12, 2021. The copyright holder for this preprint (which was not certified by peer review) is the author/funder, who has granted bioRxiv a license to display the preprint in perpetuity. It is made available under aCC-BY 4.0 International license.

\begin{tabular}{|c|c|c|}
\hline MJM4253 & MJM1198 attTn7::binK(T366Q) & This study \\
\hline MJM4254 & MJM2255 $\Delta$ binK attTn 7::binK(T366Q) & This study \\
\hline MJM4255 & MJM1198 attTn7::binK(T366A) & This study \\
\hline MJM4256 & MJM2255 $\Delta$ binK attTn 7::binK(T366A) & This study \\
\hline MJM4257 & MJM3903 pM1422 & This study \\
\hline MJM4258 & MJM4018 pM1422 & This study \\
\hline \multicolumn{3}{|l|}{ E. coli } \\
\hline MJM534 & CC118 $\lambda$ pir/pEVS104 & $(51)$ \\
\hline MJM537 & DH5a $\lambda$ pir & Laboratory Stock \\
\hline MJM542 & DH5a $\lambda$ pir/pVSV102 & $(58)$ \\
\hline MJM570 & DH5a/pEVS79 & $(51)$ \\
\hline MJM580 & DH5a $\lambda$ pir/pVSV104 & $(58)$ \\
\hline MJM637 & S17-1 גpir/pUX-BF13 & (59) \\
\hline MJM658 & DH5 $\alpha$ גpir/pEVS107 & $(60)$ \\
\hline MJM1422 & DH5a $\lambda$ pir/pM1422 & (22) \\
\hline MJM2090 & DH5a $\lambda$ pir/pLostfoX-Kan & (23) \\
\hline MJM2384 & DH5a $\lambda$ pir/pBinK & (22) \\
\hline MJM2474 & DH5a $\lambda$ pir/pTn7BinK & $(22)$ \\
\hline MJM2482 & DH5a Apir/pTn7BinK(H362Q) & JF Brooks II \\
\hline MJM3211 & DH5a $\lambda$ pir/pDAT01 & This study \\
\hline MJM3216 & DH5a $\lambda$ pir/pDAT02 & This study \\
\hline MJM3234 & DH5a $\lambda$ pir/pDAT05 & This study \\
\hline MJM3241 & DH5a $\lambda$ pir/pDAT10 & This study \\
\hline MJM3255 & DH5a $\lambda$ pir/pDAT12 & This study \\
\hline MJM3478 & m3813/pKV496 & $(50)$ \\
\hline MJM4248 & DH5a $\lambda$ pir/pDAT13 & This study \\
\hline MJM4249 & DH5a $\lambda$ pir/pDAT14 & This study \\
\hline MJM4250 & DH5a $\lambda$ pir/pDAT15 & This study \\
\hline
\end{tabular}


Table 2: Plasmid List

597

\begin{tabular}{|c|c|c|}
\hline Plasmid & Description & Source or Reference(s) \\
\hline pEVS107 & Mini-Tn7 mobilizable vector $\left(\operatorname{Kan}^{\mathrm{R}}, \mathrm{Erm}^{\mathrm{R}}\right)$ & $(60)$ \\
\hline pTn7BinK & pEVS107 carrying wild-type binK $\left(\operatorname{Kan}^{\mathrm{R}}, \mathrm{Erm}^{\mathrm{R}}\right)$ & (22) \\
\hline pTn7BinK(H362Q) & $\begin{array}{l}\text { pEVS107 carrying binK with } \mathrm{H} 362 \mathrm{Q} \text { mutation } \\
\left(\mathrm{Kan}^{\mathrm{R}}, \mathrm{Erm}^{\mathrm{R}}\right)\end{array}$ & This study \\
\hline pDAT01 & $\begin{array}{l}\text { pEVS107 carrying binK with D794A mutation } \\
\left(\operatorname{Kan}^{\mathrm{R}}, \mathrm{Erm}^{\mathrm{R}}\right)\end{array}$ & This study \\
\hline pDAT02 & $\begin{array}{l}\text { pEVS107 carrying binK with H362Q,D794A } \\
\text { mutation }\left(\operatorname{Kan}^{\mathrm{R}}{ }^{,} \mathrm{Erm}^{\mathrm{R}}\right)\end{array}$ & This study \\
\hline pDAT10 & $\begin{array}{l}\text { pEVS107 carrying binK with D794E mutation } \\
\left(\operatorname{Kan}^{\mathrm{R}}, \mathrm{Erm}^{\mathrm{R}}\right)\end{array}$ & This study \\
\hline pDAT13 & $\begin{array}{l}\text { pEVS107 carrying binK with H362Q,D794E } \\
\text { mutation }\left(\operatorname{Kan}^{\mathrm{R}}, \mathrm{Erm}^{\mathrm{R}}\right)\end{array}$ & This study \\
\hline pDAT12 & $\begin{array}{l}\text { pEVS107 carrying binK with E363A mutation } \\
\left(\operatorname{Kan}^{R}, \text { Erm }^{R}\right)\end{array}$ & This study \\
\hline pDAT14 & $\begin{array}{l}\text { pEVS107 carrying binK with T366Q mutation } \\
\left(\operatorname{Kan}^{R}, \text { Erm }^{R}\right)\end{array}$ & This study \\
\hline pDAT15 & $\begin{array}{l}\text { pEVS107 carrying binK with T366A mutation } \\
\left(\mathrm{Kan}^{\mathrm{R}}, \mathrm{Erm}^{\mathrm{R}}\right)\end{array}$ & This study \\
\hline pEVS104 & Conjugal helper plasmid $\left(\operatorname{Kan}^{\mathrm{R}}\right)$ & $(51)$ \\
\hline pUX-BF13 & Tn7 transposition helper $\left(A m p^{R}\right)$ & $(59)$ \\
\hline pVSV104 & Vector backbone for complementation $\left(\operatorname{Kan}^{\mathrm{R}}\right)$ & (58) \\
\hline pBinK & pVSV104 carrying wild-type binK $\left(\mathrm{Kan}^{\mathrm{R}}\right)$ & (22) \\
\hline pEVS79 & Vector backbone for allelic exchange $\left(\mathrm{Cam}^{\mathrm{R}}\right)$ & (51) \\
\hline pDAT05 & pEVS79 carrying sypG with D53E mutation $\left(\mathrm{Cam}^{\mathrm{R}}\right)$ & This study \\
\hline pM1422 & pTM267 sypA'-gfp+ $\left(\mathrm{Cam}^{\mathrm{R}}\right)$ & $(22)$ \\
\hline pVSV102 & Constitutive GFP $\left(\operatorname{Kan}^{\mathrm{R}}\right)$ & $(58)$ \\
\hline pVSV103 & Constitutive LacZ $\left(\operatorname{Kan}^{\mathrm{R}}\right)$ & $(58)$ \\
\hline pLostfoX-Kan & Arabinose-inducible TfoX for transformation $\left(\mathrm{Kan}^{\mathrm{R}}\right)$ & $(23)$ \\
\hline pKV496 & pEVS79 containing the FLP recombinase $\left(\operatorname{Kan}^{\mathrm{R}}\right)$ & $(50)$ \\
\hline
\end{tabular}




\begin{tabular}{|c|c|c|}
\hline Primer Name & Sequence (5'-3') & Notes \\
\hline $\begin{array}{l}\text { DAT_011F } \\
\text { BinK ext }\end{array}$ & CTTATGGGATAGCTTTAGCTCGAA & $\begin{array}{l}\text { External primer to sequence around BinK } \\
\text { gene }\end{array}$ \\
\hline $\begin{array}{l}\text { DAT_012R } \\
\text { BinK ext }\end{array}$ & TTCTTTATTAAGTGAAGGCGAACC & $\begin{array}{l}\text { External primer to sequence around BinK } \\
\text { gene }\end{array}$ \\
\hline DAT_018F tfox & TAAATAAATCCTGGTGTCCCTGTT & Screen for pLostfoX-Kan \\
\hline DAT_019R tfox & TCGCTGTTAAAAGGACAATTACAA & Screen for pLostfoX-Kan \\
\hline $\begin{array}{l}\text { DAT_064 } \\
\text { D794A F }\end{array}$ & $\begin{array}{l}\text { AGTTTTAATGGcgTGTATGATGCCGATAAT } \\
\text { G }\end{array}$ & $\begin{array}{l}\text { Site directed mutagenesis to make } \\
\text { binK(D794A), lowercase letters represent } \\
\text { mutated nucleotides }\end{array}$ \\
\hline $\begin{array}{l}\text { DAT_065 } \\
\text { D794A R }\end{array}$ & AAACTATAAGGTGACGTTTTAC & $\begin{array}{l}\text { Site directed mutagenesis to make } \\
\text { binK(D794A) }\end{array}$ \\
\hline $\begin{array}{l}\text { DAT_066 } \\
\text { D794A Fwd }\end{array}$ & GAATCGTCCAAAAATTTGTTCCGC & Screen for D794A mutation \\
\hline $\begin{array}{l}\text { DAT_067 } \\
\text { D794A RevM }\end{array}$ & CATCCATTATCGGCATCATACAcg & $\begin{array}{l}\text { Screen for D794A mutation, lowercase } \\
\text { letters represent nucleotides specific to } \\
\text { mutant }\end{array}$ \\
\hline $\begin{array}{l}\text { DAT_068 } \\
\text { D794A RevWT }\end{array}$ & CATCCATTATCGGCATCATACAgt & $\begin{array}{l}\text { Screen for D794A mutation, lowercase } \\
\text { letters represent nucleotides specific to } \\
\text { wild-type }\end{array}$ \\
\hline $\begin{array}{l}\text { DAT_071 } \\
\text { sypG_US F }\end{array}$ & $\begin{array}{l}\text { ccggtcgacggtatcgataaGATATTCTCGACTTC } \\
\text { TCACGTATG }\end{array}$ & $\begin{array}{l}\text { sypG-D53E cloning, capital letters } \\
\text { indicate homology to template }\end{array}$ \\
\hline $\begin{array}{l}\text { DAT_072 } \\
\text { sypG_US R }\end{array}$ & $\begin{array}{l}\text { tcgagaatcaccaaatgTGGTGGATTCTTTTCCA } \\
\text { TAAATGC }\end{array}$ & $\begin{array}{l}\text { sypG-D53E cloning, capital letters } \\
\text { indicate homology to template }\end{array}$ \\
\hline $\begin{array}{l}\text { DAT_074 } \\
\text { sypG_DS R }\end{array}$ & $\begin{array}{l}\text { gcaggaattcgatatcaagcCTGGAATATAATGCC } \\
\text { GCTTTGTAG }\end{array}$ & $\begin{array}{l}\text { sypG-D53E cloning, capital letters } \\
\text { indicate homology to template }\end{array}$ \\
\hline $\begin{array}{l}\text { DAT_077 } \\
\text { sypG_DS F }\end{array}$ & CATTTGGTGATTCTCGAaTTGAAACTGCC & $\begin{array}{l}\text { sypG-D53E cloning, lowercase letter } \\
\text { represents mutated nucleotide }\end{array}$ \\
\hline $\begin{array}{l}\text { DAT_078 sypG } \\
\text { seq1 }\end{array}$ & CATGAAGGTTCTGGTTTAGGG & pEVS79 sypG-D53E sequencing \\
\hline $\begin{array}{l}\text { DAT_079 sypG } \\
\text { seq2 }\end{array}$ & CCGCTCTCTATCTGATAC & pEVS79 sypG-D53E sequencing \\
\hline $\begin{array}{l}\text { DAT_080 sypG } \\
\text { seq3 }\end{array}$ & GCATTAGAGTTTGAAGCG & pEVS79 sypG-D53E sequencing \\
\hline $\begin{array}{l}\text { DAT_081 sypG } \\
\text { seq4 }\end{array}$ & GATATGTCAGGGCAGGATG & pEVS79 sypG-D53E sequencing \\
\hline $\begin{array}{l}\text { DAT_082 sypG } \\
\text { seq5 }\end{array}$ & GTAAACGCAGCAATAAACC & pEVS79 sypG-D53E sequencing \\
\hline DAT_083 sypG & CGCAAAAGAAGATCATAA & pEVS79 sypG-D53E sequencing \\
\hline
\end{tabular}




\begin{tabular}{|c|c|c|}
\hline seq6 & & \\
\hline $\begin{array}{l}\text { DAT_084 sypG } \\
\text { seq7 }\end{array}$ & GATGGTAATGTTCTTAATG & pEVS79 sypG-D53E sequencing \\
\hline $\begin{array}{l}\text { DAT_085 sypG } \\
\text { seq8 }\end{array}$ & CCATTGGGCGAATTACAC & pEVS79 sypG-D53E sequencing \\
\hline $\begin{array}{l}\text { DAT_086 sypG } \\
\text { seq9 }\end{array}$ & GAATAGGCACAACATGGAC & pEVS79 sypG-D53E sequencing \\
\hline $\begin{array}{l}\text { DAT_087 sypG } \\
\text { seq10 }\end{array}$ & CCTGTACCGCTTTCACCA & pEVS79 sypG-D53E sequencing \\
\hline $\begin{array}{l}\text { DAT_088 sypG } \\
\text { seq11 }\end{array}$ & CATAAATGCCTTCGCTTG & pEVS79 sypG-D53E sequencing \\
\hline $\begin{array}{l}\text { DAT_089 sypG } \\
\text { seq12 }\end{array}$ & GATGGTTTCTACTCGCTC & pEVS79 sypG-D53E sequencing \\
\hline $\begin{array}{l}\text { DAT_090 sypG } \\
\text { seq13 }\end{array}$ & CATCCATTTCAGGCATAG & pEVS79 sypG-D53E sequencing \\
\hline $\begin{array}{l}\text { DAT_091 sypG } \\
\text { seq14 }\end{array}$ & GCTGTTATCTGCCATAGT & pEVS79 sypG-D53E sequencing \\
\hline $\begin{array}{l}\text { DAT_092 } \\
\text { D53E Fwd }\end{array}$ & GAGTTTAATGAATCAACAGAAGAGC & sypG-D53E screen \\
\hline $\begin{array}{l}\text { DAT_093 } \\
\text { D53E RevMT }\end{array}$ & CCCTGACATATCTGGCAGTTTCAAt & $\begin{array}{l}\text { sypG-D53E screen, lowercase letters } \\
\text { represent nucleotides specific to mutant }\end{array}$ \\
\hline $\begin{array}{l}\text { DAT_094 } \\
\text { D53E RevWT }\end{array}$ & CCCTGACATATCTGGCAGTTTCAAa & $\begin{array}{l}\text { sypG-D53E screen, lowercase letters } \\
\text { represent nucleotides specific to wild- } \\
\text { type }\end{array}$ \\
\hline $\begin{array}{l}\text { DAT_095 sypG } \\
\text { fwd }\end{array}$ & CTACAGCAAGCCAGAAATGAAGCAG & $\begin{array}{l}\text { Amplify around sypG insert area on } \\
\text { pEVS79 }\end{array}$ \\
\hline $\begin{array}{l}\text { DAT_096 sypG } \\
\text { rev }\end{array}$ & GGGTGCCTTTTGATTGAATTAAGTTC & $\begin{array}{l}\text { Amplify around sypG insert area on } \\
\text { pEVS79 }\end{array}$ \\
\hline $\begin{array}{l}\text { DAT_106 } \\
\text { D794E F }\end{array}$ & TTTTAATGGAgTGTATGATGCC & $\begin{array}{l}\text { Site directed mutagenesis to make } \\
\text { binK(D794E), lowercase letters represent } \\
\text { mutated nucleotides }\end{array}$ \\
\hline $\begin{array}{l}\text { DAT_107 } \\
\text { D794E R }\end{array}$ & CTAAACTATAAGGTGACGTTTTAC & $\begin{array}{l}\text { Site directed mutagenesis to make } \\
\text { binK(D794E) }\end{array}$ \\
\hline $\begin{array}{l}\text { DAT_109 } \\
\text { E363A_F }\end{array}$ & ATGTCACACGctATTCGAACAC & $\begin{array}{l}\text { Site directed mutagenesis to make } \\
\text { binK(E363A), lowercase letters represent } \\
\text { mutated nucleotides }\end{array}$ \\
\hline $\begin{array}{l}\text { DAT_110 } \\
\text { E363_R }\end{array}$ & ATTAGCTAAAAATGAACTTTTGG & $\begin{array}{l}\text { Site directed mutagenesis to make } \\
\text { binK(E363A) }\end{array}$ \\
\hline $\begin{array}{l}\text { DAT_111 } \\
\text { T366A_F }\end{array}$ & CGAAATTCGAgcACCTCTAAATG & $\begin{array}{l}\text { Site directed mutagenesis to make } \\
\text { binK(T366A), lowercase letters represent } \\
\text { mutated nucleotides }\end{array}$ \\
\hline
\end{tabular}




\begin{tabular}{|c|c|c|}
\hline $\begin{array}{l}\text { DAT_112 } \\
\text { T366_R }\end{array}$ & TGTGACATATTAGCTAAAAATG & $\begin{array}{l}\text { Site directed mutagenesis to make binK } \\
\text { T366 mutations }\end{array}$ \\
\hline $\begin{array}{l}\text { DAT_114 } \\
\text { T366Q_F }\end{array}$ & CGAAATTCGAcaACCTCTAAATGGCATC & $\begin{array}{l}\text { Site directed mutagenesis to make } \\
\text { binK(T366Q), lowercase letters represent } \\
\text { mutated nucleotides }\end{array}$ \\
\hline $\begin{array}{l}\text { DAT_118 } \\
\text { D794E_RevWT }\end{array}$ & CATCCATTATCGGCATCATACAg & $\begin{array}{l}\text { Screen for D794E mutation, lowercase } \\
\text { letters represent nucleotides specific to } \\
\text { wild-type }\end{array}$ \\
\hline $\begin{array}{l}\text { DAT_119 } \\
\text { D794E_RevM }\end{array}$ & CATCCATTATCGGCATCATACAC & $\begin{array}{l}\text { Screen for D794E mutation, lowercase } \\
\text { letters represent nucleotides specific to } \\
\text { mutant }\end{array}$ \\
\hline $\begin{array}{l}\text { DAT_120 } \\
\text { E363A_RevM }\end{array}$ & CCATTTAGAGGTGTTCGAATag & $\begin{array}{l}\text { Screen for E363A mutation, lowercase } \\
\text { letters represent nucleotides specific to } \\
\text { mutant }\end{array}$ \\
\hline $\begin{array}{l}\text { DAT_121 } \\
\text { E363A_RevWT }\end{array}$ & CCATTTAGAGGTGTTCGAATtt & $\begin{array}{l}\text { Screen for E363A mutation, lowercase } \\
\text { letters represent nucleotides specific to } \\
\text { wild-type }\end{array}$ \\
\hline $\begin{array}{l}\text { DAT_122 } \\
\text { E363A_Fwd }\end{array}$ & GGTTGATCGGTGTTATTGAATC & Screen for E363A mutation \\
\hline $\begin{array}{l}\text { DAT_257 T336 } \\
\text { RevWT }\end{array}$ & CATACCAATGATGCCATTTAGAGGTgt & $\begin{array}{l}\text { Screen for T366 mutations, lowercase } \\
\text { letters represent nucleotides specific to } \\
\text { wild-type }\end{array}$ \\
\hline $\begin{array}{l}\text { DAT_259 T366 } \\
\operatorname{RevQ}\end{array}$ & CATACCAATGATGCCATTTAGAGGTtg & $\begin{array}{l}\text { Screen for T366 mutations, lowercase } \\
\text { letters represent nucleotides specific to } \\
\text { T366Q mutant }\end{array}$ \\
\hline $\begin{array}{l}\text { DAT_260 T366 } \\
\text { RevA }\end{array}$ & CATACCAATGATGCCATTTAGAGGTgc & $\begin{array}{l}\text { Screen for T366 mutations, lowercase } \\
\text { letters represent nucleotides specific to } \\
\text { T366A mutant }\end{array}$ \\
\hline $\begin{array}{l}\text { DAT_261 T366 } \\
\text { Fwd }\end{array}$ & CGCTGTTGATGAAAGTATGTATGTTGTAG & Screen for T366 mutations \\
\hline Tn7 site $F$ & TGTTGATGATACCATTGAAGCTAAA & Amplify around atf $T n 7$ site \\
\hline Tn7 site $R$ & CTTGCTGTATGTATTTGCTGATGA & Amplify around atf $T n 7$ site \\
\hline pEVS107 F & ACCTATCAAGGTGTACTGCCTTCC & $\begin{array}{l}\text { Sequences around pEVS107 multiple } \\
\text { cloning site }\end{array}$ \\
\hline pEVS107 R & GTCGTTAAATGCCCTTTACCTGT & $\begin{array}{l}\text { Sequences around pEVS107 multiple } \\
\text { cloning site }\end{array}$ \\
\hline $\mathrm{MRH} 001$ & TTATCGATACCGTCGACC & Linearizes pEVS79 for cloning \\
\hline MRH002 & GCTTGATATCGAATTCCTG & Linearizes pEVS79 for cloning \\
\hline M13 Rev (-48) & AGCGGATAACAATTTCACACAGG & Amplifies around plasmid insertions \\
\hline M13 For $(-41)$ & CGCCAGGGTTTTCCCAGTCACGAC & Amplifies around plasmid insertions \\
\hline
\end{tabular}




\begin{tabular}{|c|c|c|}
\hline JFB_359 & AAATGATAATCGCTGGTC & Sequencing of binK \\
\hline JFB_361 & GATGTTCATCAAGCATTA & Sequencing of binK \\
\hline JFB_362 & GAGGTGTTCGAATTTCGT & Sequencing of binK \\
\hline JFB_363 & GAGCGAAAGTCTCATCAG & Sequencing of binK \\
\hline JFB_364 & AAACCTCAGACCATGAAA & Sequencing of bink \\
\hline JFB_365 & GGAAAGAGAATGATTAAG & Sequencing of binK \\
\hline JFB_366 & ATTCAAAGAATATGGTGC & Sequencing of bink \\
\hline JFB_371 & CTATTTTATTGGCTTGTG & Sequencing of bink \\
\hline JFB_372 & AACTGAAACCGATTTAAC & Sequencing of binK \\
\hline JFB_373 & ATGCCGTTAAATTTACTC & Sequencing of binK \\
\hline JFB_374 & TTGAGGTGATTGAGCCAA & Sequencing of binK \\
\hline JFB_375 & TTGAACGTACAATTGAAG & Sequencing of binK \\
\hline JFB_376 & TAGATATGGTGATGAGTA & Sequencing of binK \\
\hline JFB_377 & ACTGAATTACGTTTAACG & Sequencing of binK \\
\hline JFB_426 & GCTAATATGTCACAAGAAATTCGAACACC & $\begin{array}{l}\text { Site-directed mutagenesis to make } \\
\text { pTn7BinK (H362Q) }\end{array}$ \\
\hline JFB_427 & GGTGTTCGAATTTCTTGTGACATATTAGC & $\begin{array}{l}\text { Site-directed mutagenesis to make } \\
\text { pTn7BinK }(\mathrm{H} 362 \mathrm{Q})\end{array}$ \\
\hline KMB_081 & $\begin{array}{l}\text { GTGTGATGCAGATATAAAAAATCCCTGAT } \\
\text { CTTAATC }\end{array}$ & F0 for ES114 rscS deletion \\
\hline KMB_082 & CGAACTTCCCCACCAGCTAAAATC & F1 for ES114 rscS deletion \\
\hline KMB_083 & $\begin{array}{l}\text { CTGGCGAAGCATATATAAGAAGCTCGTCT } \\
\text { CGTCATTGCATTAGCTCCTATAAAATAGT } \\
\text { CTGTTTGG }\end{array}$ & R1-LL for ES114 rscS deletion \\
\hline KMB_084 & CACTACATTGCCGTAGAAAGAGACATCAC & FW for ES114 rscS deletion \\
\hline KMB_085 & $\begin{array}{l}\text { CAGCTTGTTTACCTTTACCTGTTAGAGTA } \\
\text { TGG }\end{array}$ & RW for ES114 rscS deletion \\
\hline KMB_086 & $\begin{array}{l}\text { GACTTGACCTGGATGTCTCTACCCACAAG } \\
\text { ATCGGAGAAGTATGAAACACAATAAACTT } \\
\text { CGTCATAAAAAAAGG }\end{array}$ & F2-RL for ES114 rscS deletion \\
\hline KMB_087 & $\begin{array}{l}\text { CGTACTATGGTGTTTAATATCAATACACTT } \\
\text { CAATGGG }\end{array}$ & R2 for ES114 rscS deletion \\
\hline KMB_088 & CTCTCGTGCTGTCATTCTTGACCAC & R0 for ES114 rscS deletion \\
\hline HB8 & $\begin{array}{l}\text { ACAAAATTTTAAGATACTGCACTATCAACA } \\
\text { CACTCTTAAG }\end{array}$ & Sequencing of ES114 $\Delta r s c S$ \\
\hline
\end{tabular}


bioRxiv preprint doi: https://doi.org/10.1101/2021.03.29.437627; this version posted May 12, 2021. The copyright holder for this preprint (which was not certified by peer review) is the author/funder, who has granted bioRxiv a license to display the preprint in perpetuity. It is made available under aCC-BY 4.0 International license.

602

\begin{tabular}{|c|c|c|}
\hline HB9 & $\begin{array}{l}\text { GGGAGGAAATAAtCTAGAATGCGAGAGTA } \\
\text { GG }\end{array}$ & Sequencing of ES114 $\Delta r s c S$ \\
\hline HB41 & $\begin{array}{l}\text { CGATCTTGTGGGTAGAGACATCCAGGTC } \\
\text { AAGTCCAGCCCCGCTCTAGTTTGGGAAT } \\
\text { CAAGTGCATGAGCGCTGAAG }\end{array}$ & Sequencing of ES114 $\Delta r s c S$ \\
\hline HB42 & $\begin{array}{l}\text { ACGAGACGAGCTTCTTATATATGCTTCGC } \\
\text { CAG }\end{array}$ & Sequencing of ES114 $\Delta r s c S$ \\
\hline
\end{tabular}

603 


\section{REFERENCES}

605

606

607

608

609

610

611

612

613

614

615

616

617

618

619

620

621

622

623

624

1. Ruby E, Henderson B, McFall-Ngai M. 2004. Microbiology. We get by with a little help from our (little) friends. Science 303:1305-1307.

2. McFall-Ngai MJ. 2014. The importance of microbes in animal development: lessons from the squid-Vibrio symbiosis. Annu Rev Microbiol 68:177-194.

3. Nyholm SV, Stabb EV, Ruby EG, McFall-Ngai MJ. 2000. Establishment of an animalbacterial association: recruiting symbiotic vibrios from the environment. Proc Natl Acad Sci U S A 97:10231-10235.

4. Mandel MJ, Dunn AK. 2016. Impact and influence of the natural Vibrio-squid symbiosis in understanding bacterial-animal interactions. Front Microbiol 7:1982.

5. Visick KL, Ruby EG. 2006. Vibrio fischeri and its host: it takes two to tango. Curr Opin Microbiol 9:632-638.

6. Ruby EG. 1996. Lessons from a cooperative, bacterial-animal association: the Vibrio fischeri-Euprymna scolopes light organ symbiosis. Annu Rev Microbiol 50:591-624.

7. Ruby EG, McFall-Ngai MJ. 1992. A squid that glows in the night: development of an animalbacterial mutualism. J Bacteriol 174:4865-4870.

8. Koch EJ, Miyashiro T, McFall-Ngai MJ, Ruby EG. 2014. Features governing symbiont persistence in the squid-vibrio association. Mol Ecol 23:1624-1634.

9. Nyholm SV, McFall-Ngai MJ. 2004. The winnowing: establishing the squid-Vibrio symbiosis. Nat Rev Microbiol 2:632-642.

10. Yip ES, Geszvain K, DeLoney-Marino CR, Visick KL. 2006. The symbiosis regulator rscS 
controls the syp gene locus, biofilm formation and symbiotic aggregation by Vibrio fischeri. Mol Microbiol 62:1586-1600.

11. Yip ES, Grublesky BT, Hussa EA, Visick KL. 2005. A novel, conserved cluster of genes promotes symbiotic colonization and $\sigma^{54}$-dependent biofilm formation by Vibrio fischeri. Mol Microbiol 57:1485-1498.

12. Visick KL. 2009. An intricate network of regulators controls biofilm formation and colonization by Vibrio fischeri. Mol Microbiol 74:782-789.

13. Mandel MJ, Wollenberg MS, Stabb EV, Visick KL, Ruby EG. 2009. A single regulatory gene is sufficient to alter bacterial host range. Nature 458:215-218.

14. Pankey SM, Foxall RL, Ster IM, Perry LA, Schuster BM, Donner RA, Coyle M, Cooper VS, Whistler CA. 2017. Host-selected mutations converging on a global regulator drive an adaptive leap towards symbiosis in bacteria. Elife 6:e24414.

15. Rotman ER, Bultman KM, Brooks JF 2nd, Gyllborg MC, Burgos HL, Wollenberg MS, Mandel MJ. 2019. Natural strain variation reveals diverse biofilm regulation in squidcolonizing Vibrio fischeri. J Bacteriol $201: e 00033-19$.

16. Geszvain K, Visick KL. 2008. The hybrid sensor kinase RscS integrates positive and negative signals to modulate biofilm formation in Vibrio fischeri. J Bacteriol 190:4437-4446.

17. Norsworthy AN, Visick KL. 2015. Signaling between two interacting sensor kinases promotes biofilms and colonization by a bacterial symbiont. Mol Microbiol 96:233-248.

644 18. Hussa EA, Darnell CL, Visick KL. 2008. RscS functions upstream of SypG to control the 645 syp locus and biofilm formation in Vibrio fischeri. J Bacteriol 190:4576-4583.

646 19. Darnell CL, Hussa EA, Visick KL. 2008. The putative hybrid sensor kinase SypF 
coordinates biofilm formation in Vibrio fischeri by acting upstream of two response regulators, SypG and VpsR. J Bacteriol 190:4941-4950.

20. Ray VA, Eddy JL, Hussa EA, Misale M, Visick KL. 2013. The syp enhancer sequence plays a key role in transcriptional activation by the $\sigma^{54}$-dependent response regulator SypG and in biofilm formation and host colonization by Vibrio fischeri. J Bacteriol 195:5402-5412.

21. Morris AR, Visick KL. 2013. The response regulator SypE controls biofilm formation and colonization through phosphorylation of the syp-encoded regulator SypA in Vibrio fischeri. Mol Microbiol 87:509-525.

22. Brooks JF 2nd, Mandel MJ. 2016. The histidine kinase BinK Is a negative regulator of biofilm formation and squid colonization. J Bacteriol 198:2596-2607.

23. Brooks JF 2nd, Gyllborg MC, Cronin DC, Quillin SJ, Mallama CA, Foxall R, Whistler C, Goodman AL, Mandel MJ. 2014. Global discovery of colonization determinants in the squid symbiont Vibrio fischeri. Proc Natl Acad Sci U S A 111:17284-17289.

24. Tischler AH, Lie L, Thompson CM, Visick KL. 2018. Discovery of calcium as a biofilmpromoting signal for Vibrio fischeri reveals new phenotypes and underlying regulatory

25. Thompson CM, Tischler AH, Tarnowski DA, Mandel MJ, Visick KL. 2019. Nitric oxide inhibits biofilm formation by Vibrio fischeri via the nitric oxide sensor HnoX. Mol Microbiol

26. Marchler-Bauer A, Bryant SH. 2004. CD-Search: protein domain annotations on the fly. Nucleic Acids Res 32:W327-31. 

A, Gough J, Haft DH, Letunic I, Marchler-Bauer A, Mi H, Natale DA, Necci M, Orengo CA, Pandurangan AP, Rivoire C, Sigrist CJA, Sillitoe I, Thanki N, Thomas PD, Tosatto SCE, Wu $\mathrm{CH}$, Bateman A, Finn RD. 2021. The InterPro protein families and domains database: 20

28. Letunic I, Khedkar S, Bork P. 2021. SMART: recent updates, new developments and status years on. Nucleic Acids Res 49:D344-D354. SCE, Paladin L, Raj S, Richardson LJ, Finn RD, Bateman A. 2021. Pfam: The protein families database in 2021. Nucleic Acids Res 49:D412-D419.

30. Wise AA, Fang F, Lin Y-H, He F, Lynn DG, Binns AN. 2010. The receiver domain of hybrid histidine kinase VirA: an enhancing factor for vir gene expression in Agrobacterium

31. Wise AA, Binns AN. 2015. The receiver of the Agrobacterium tumefaciens VirA histidine kinase forms a stable interaction with VirG to activate virulence gene expression. Front

32. Singh P, Brooks JF 2nd, Ray VA, Mandel MJ, Visick KL. 2015. CysK plays a role in biofilm formation and colonization by Vibrio fischeri. Appl Environ Microbiol 81:5223-5234.

33. Freeman JA, Lilley BN, Bassler BL. 2000. A genetic analysis of the functions of LuxN: a two-component hybrid sensor kinase that regulates quorum sensing in Vibrio harveyi. Mol

34. Gao R, Stock AM. 2009. Biological insights from structures of two-component proteins. Annu Rev Microbiol 63:133-154. 
35. Bhate MP, Molnar KS, Goulian M, DeGrado WF. 2015. Signal transduction in histidine kinases: insights from new structures. Structure 23:981-994.

36. Atkinson MR, Ninfa AJ. 1993. Mutational analysis of the bacterial signal-transducing protein kinase/phosphatase nitrogen regulator II (NRII or NtrB). J Bacteriol 175:7016-7023.

37. Willett JW, Kirby JR. 2012. Genetic and biochemical dissection of a HisKA domain identifies residues required exclusively for kinase and phosphatase activities. PLoS Genet 8:e1003084.

38. Huynh TN, Noriega CE, Stewart V. 2010. Conserved mechanism for sensor phosphatase control of two-component signaling revealed in the nitrate sensor NarX. Proc Natl Acad Sci U S A 107:21140-21145.

39. Huynh TN, Stewart V. 2011. Negative control in two-component signal transduction by transmitter phosphatase activity. Mol Microbiol 82:275-286.

40. Dutta R, Yoshida T, Inouye M. 2000. The critical role of the conserved Thr247 residue in the functioning of the osmosensor EnvZ, a histidine kinase/phosphatase, in Escherichia

41. Wayne KJ, Li S, Kazmierczak KM, Tsui H-CT, Winkler ME. 2012. Involvement of WalK (VicK) phosphatase activity in setting WalR (VicR) response regulator phosphorylation level and limiting cross-talk in Streptococcus pneumoniae D39 cells. Mol Microbiol 86:645-660.

42. Thompson CM, Marsden AE, Tischler AH, Koo J, Visick KL. 2018. Vibrio fischeri biofilm formation prevented by a trio of regulators. Appl Environ Microbiol 84:e01257-18. colonization of Euprymna scolopes by Vibrio fischeri. J Bacteriol 183:835-842. 
714 44. Kinoshita-Kikuta E, Kinoshita E, Eguchi Y, Koike T. 2016. Validation of cis and trans modes in multistep phosphotransfer signaling of bacterial tripartite sensor kinases by using Phos-

45. Teran-Melo JL, Peña-Sandoval GR, Silva-Jimenez H, Rodriguez C, Alvarez AF, Georgellis Tag SDS-PAGE. PLoS One 11:e0148294. D. 2018. Routes of phosphoryl group transfer during signal transmission and signal decay in the dimeric sensor histidine kinase ArcB. J Biol Chem 293:13214-13223.

46. Jacob-Dubuisson F, Mechaly A, Betton J-M, Antoine R. 2018. Structural insights into the signalling mechanisms of two-component systems. Nat Rev Microbiol 16:585-593.

47. Chang $\mathrm{CH}$, Zhu J, Winans SC. 1996. Pleiotropic phenotypes caused by genetic ablation of the receiver module of the Agrobacterium tumefaciens VirA protein. J Bacteriol 178:47104716.

48. Altura MA, Heath-Heckman EAC, Gillette A, Kremer N, Krachler A-M, Brennan C, Ruby EG, Orth K, McFall-Ngai MJ. 2013. The first engagement of partners in the Euprymna scolopes-Vibrio fischeri symbiosis is a two-step process initiated by a few environmental symbiont cells. Environ Microbiol 15:2937-2950.

49. Le Roux F, Binesse J, Saulnier D, Mazel D. 2007. Construction of a Vibrio splendidus mutant lacking the metalloprotease gene vsm by use of a novel counterselectable suicide vector. Appl Environ Microbiol 73:777-784.

50. Visick KL, Hodge-Hanson KM, Tischler AH, Bennett AK, Mastrodomenico V. 2018. Tools for Rapid Genetic Engineering of Vibrio fischeri. Appl Environ Microbiol 84:e00850-18. and members of the Vibrionaceae. Methods Enzymol 358:413-426. 
52. Burgos HL, Burgos EF, Steinberger AJ, Suen G, Mandel MJ. 2020. Multiplexed competition in a synthetic squid light organ microbiome using barcode-tagged gene deletions. mSystems 5:e00846-20.

53. Brooks JF 2nd, Gyllborg MC, Kocher AA, Markey LEH, Mandel MJ. 2015. TfoX-based genetic mapping identifies Vibrio fischeri strain-level differences and reveals a common lineage of laboratory strains. J Bacteriol 197:1065-1074.

54. Pollack-Berti A, Wollenberg MS, Ruby EG. 2010. Natural transformation of Vibrio fischeri requires tfoX and tfoY. Environ Microbiol 12:2302-2311.

744 55. Naughton LM, Mandel MJ. 2012. Colonization of Euprymna scolopes squid by Vibrio fischeri. J Vis Exp e3758.

56. Boettcher KJ, Ruby EG. 1990. Depressed light emission by symbiotic Vibrio fischeri of the sepiolid squid Euprymna scolopes. J Bacteriol 172:3701-3706.

57. Mandel MJ, Stabb EV, Ruby EG. 2008. Comparative genomics-based investigation of resequencing targets in Vibrio fischeri: focus on point miscalls and artefactual expansions. BMC Genomics 9:138.

58. Dunn AK, Millikan DS, Adin DM, Bose JL, Stabb EV. 2006. New rfp- and pES213-derived tools for analyzing symbiotic Vibrio fischeri reveal patterns of infection and lux expression in situ. Appl Environ Microbiol 72:802-810.

59. Bao Y, Lies DP, Fu H, Roberts GP. 1991. An improved Tn7-based system for the singlecopy insertion of cloned genes into chromosomes of gram-negative bacteria. Gene 109:167-168. 
bioRxiv preprint doi: https://doi.org/10.1101/2021.03.29.437627; this version posted May 12, 2021. The copyright holder for this preprint (which

was not certified by peer review) is the author/funder, who has granted bioRxiv a license to display the preprint in perpetuity. It is made available under aCC-BY 4.0 International license.

758 during infection of Euprymna scolopes. Appl Environ Microbiol 69:5928-5934.

759 61. Madeira F, Park YM, Lee J, Buso N, Gur T, Madhusoodanan N, Basutkar P, Tivey ARN,

760 Potter SC, Finn RD, Lopez R. 2019. The EMBL-EBI search and sequence analysis tools

761 APIs in 2019. Nucleic Acids Res 47:W636-W641.

762 
Figure 1: BinK signaling and domain organization

A) Model of the biofilm pathway in strain ES114 as is relevant for this study. RscS signals

767 through SypF to SypG, which is a $\sigma^{54}$-dependent transcriptional activator of the syp locus.

768 Expression of the syp locus is required for biofilm formation. BinK inhibits biofilm production and

769 feeds into the pathway at an unknown location at or above SypG. (OM, outer membrane; IM,

770 inner membrane). B) Putative subcellular localization of a BinK homodimer C) BinK domain

771 diagram. Positions of key residues and the epitope used to generate the BinK peptide antibody

772 (722-742) are annotated. (TM, predicted transmembrane domains).

773

774 Figure 2: BinK requires $\mathrm{H} 362$ and D794 to inhibit colony biofilms.

775 A) Genome representations of the different strains used to assess binK alleles. The parent

776 ES114 rscS* strain (MJM1198) was used to induce biofilm formation for wrinkled colony assays

777 on plates. The att Tn 7 site is located on chromosome I and the native locus of binK is on

778 chromosome II. mut designates a mutant allele of binK, while $\Delta$ indicates a clean deletion at that

779 locus. B) Wrinkled colony assay of the strains indicated, grown at $28^{\circ} \mathrm{C}$ for 48 hours. Mutations

780 (or WT control) expressed at the atfTn7 site are listed beside each spot. In the left column, the

781 expressed allele is the only binK allele in the cell, while in the right column wild-type binK is

782 additionally present at its native locus. Scale bar is $2 \mathrm{~mm}$. C) Western blot of whole cell lysates

783 assessed with a peptide antibody against BinK. Arrow indicates BinK, which is predicted to be

$78497 \mathrm{kDa}(61)$, and which is absent in the strain that does not encode the protein.

786 Figure 3: RscS is not required for squid colonization in a strain lacking BinK

787 Bacteria were inoculated into FSIO containing squid and allowed to colonize for 3 hours. Squid

788 were washed and then maintained for two days to allow establishment of the symbiosis. Shown 
are data on the luminescence $(\mathrm{A})$ and CFU (B) per light organ (LO) at 48 hpi.Each dot represents an individual animal. The dashed line indicates the limit of detection for CFU/LO. For

791 both graphs, data is pooled from three replicate experiments. Bars represent the median for

792 each strain with a 95\% confidence interval. Statistical significance was calculated using Kruskal-

793 Wallis test with Dunn's multiple comparison tests. (ns, not significant; ${ }^{* * * *}, p<0.0001$ )

Figure 4: RscS does not impact aggregation in a strain lacking BinK

796 Imaging of bacterial aggregates in host mucus using fluorescence microscopy with the Zeiss

797 Axio Zoom fluorescent microscope. Squid were inoculated with $V$. fischeri cells that

798 constitutively express GFP from the pVSV102 plasmid and imaged at 3-4 hpi. A)

799 Representative images of aggregates of approximately median size for each strain. Scale bar is

$800200 \mu \mathrm{m}$ with all panels at the same scale. B) Quantification of aggregate area. Each dot

801 represents one aggregate. A measure of zero indicates no aggregate was present. Significance

802 was determined with a Kruskal-Wallis test and Dunn's multiple comparison tests (ns, not

803 significant; $\left.{ }^{* *}, \mathrm{p}<0.01 ;^{* * *}, \mathrm{p}<0.001\right)$. The median area with a $95 \%$ confidence interval is

804 displayed for each group. The data is pooled from two replicate experiments. WT = wild-type

805 ES114 (MJM1100).

806

807 Figure 5: RscS is required for competitive fitness in a $\Delta$ binK background. Competitive

808 fitness of the indicated strains (unlabeled) compared to a $\Delta$ binK strain (labeled with LacZ).

809 Squid were exposed to a mixed inoculum of the two strains for 3 hours, then assessed at $48 \mathrm{hpi}$.

810 Blue vs white CFU counts on LBS-Xgal were used to determine the representation of each

811 strain in the competition. The competitive index is equal to the $\log _{10}$-transformed value of the

812 ratio (indicated strain/ $\Delta$ binK strain) after competition normalized to its ratio in the input inoculum.

813 Each point represents the competitive index from an individual squid. The median ratio with a 
$81495 \%$ confidence interval is represented by the bar. Statistical significance was calculated with a

815 Mann-Whitney U-test $\left.{ }^{* \star * *}, \mathrm{p}<0.0001\right)$.

816

817 Figure 6: RscS does not alter syp production on agar in strains lacking BinK

818 syp'-gfp ${ }^{+}$transcriptional reporter activity normalized to constitutive mCherry from strains carrying

819 pM1422. A, B) Each strain was spotted onto LBS or LBS-Calcium and grown for 48 hours at

$82025^{\circ} \mathrm{C}$. Images were taken on both a Zeiss Axio Zoom fluorescent microscope and Leica

821 brightfield stereoscope. Scale bar in the bottom right of $B$ is $2 \mathrm{~mm}$ and all panels in $A$ and $B$ are

822 at the same scale. C) Quantification of the fluorescence intensity. GFP intensity of the entire

823 colony was normalized to mCherry intensity. Each bar represents the average GFP/mCherry of

824 five different colonies from replicate experiments on two distinct days. Error bars are standard

825 deviations. Statistical significance was determined with a two-way ANOVA analyzing the effect

826 of strain background and media on fluorescence with Tukey's test for multiple comparisons. (ns,

827 not significant; $\left.{ }^{*}, p<0.05 ;{ }^{* * * *}, p<0.0001\right)$

828

829 Figure 7: BinK inhibits sypA transcription in the crypts

830 Imaging of $V$. fischeri containing the pM1422 sypA'-gfp reporter plasmid (that encodes

831 constitutive mCherry) while aggregating in host mucus at 3-4 hpi (A, quantified in C) or in host

832 crypts at 48 hpi (B, quantified in D). For quantification, intensity of GFP and mCherry was

833 measured for each individual aggregate or crypt, background signal was subtracted, and GFP

834 was normalized to the mCherry level. Zen Blue software was used to collect signal and

835 background measurements. Each dot represents an individual aggregate or crypt. Bars

836 represent the median GFP/mCherry ratio with 95\% confidence intervals. Statistical significance

837 within each location was determined by a Kruskal-Wallis test with Dunn's multiple comparison

838 tests (ns, not significant; ${ }^{* *}, p<0.01$ ). Data for each bacterial location is pooled from at least 3

839 replicate experiments that each contained 4-8 squid per strain. 
A

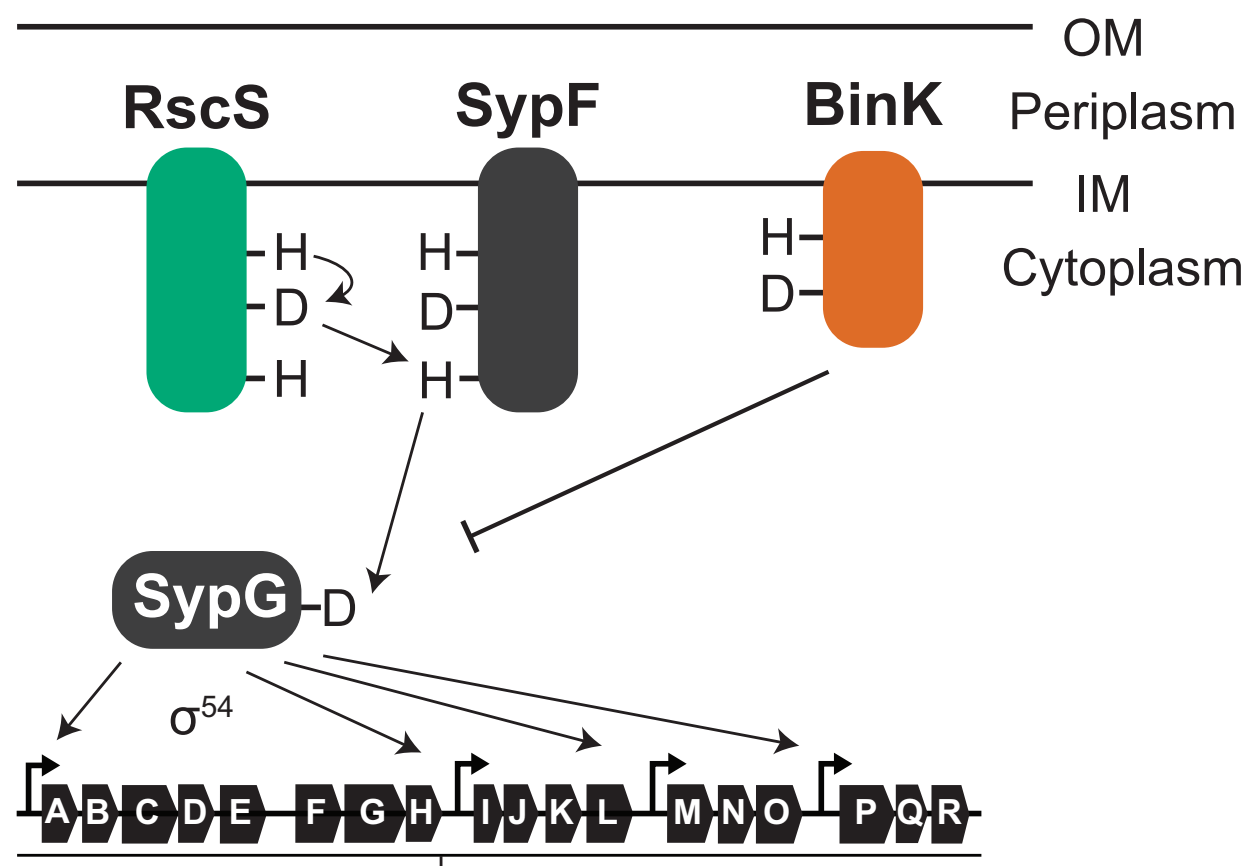

B BinK

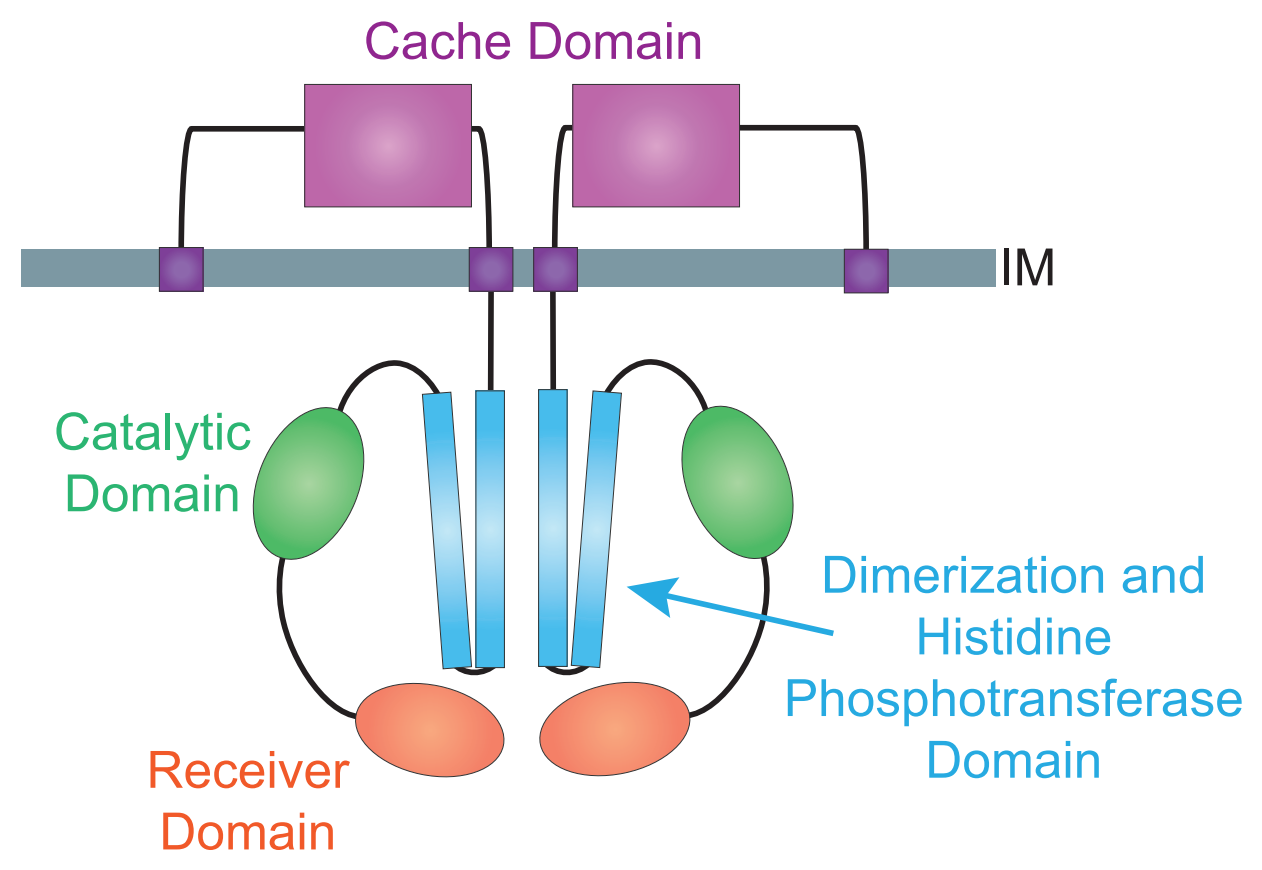




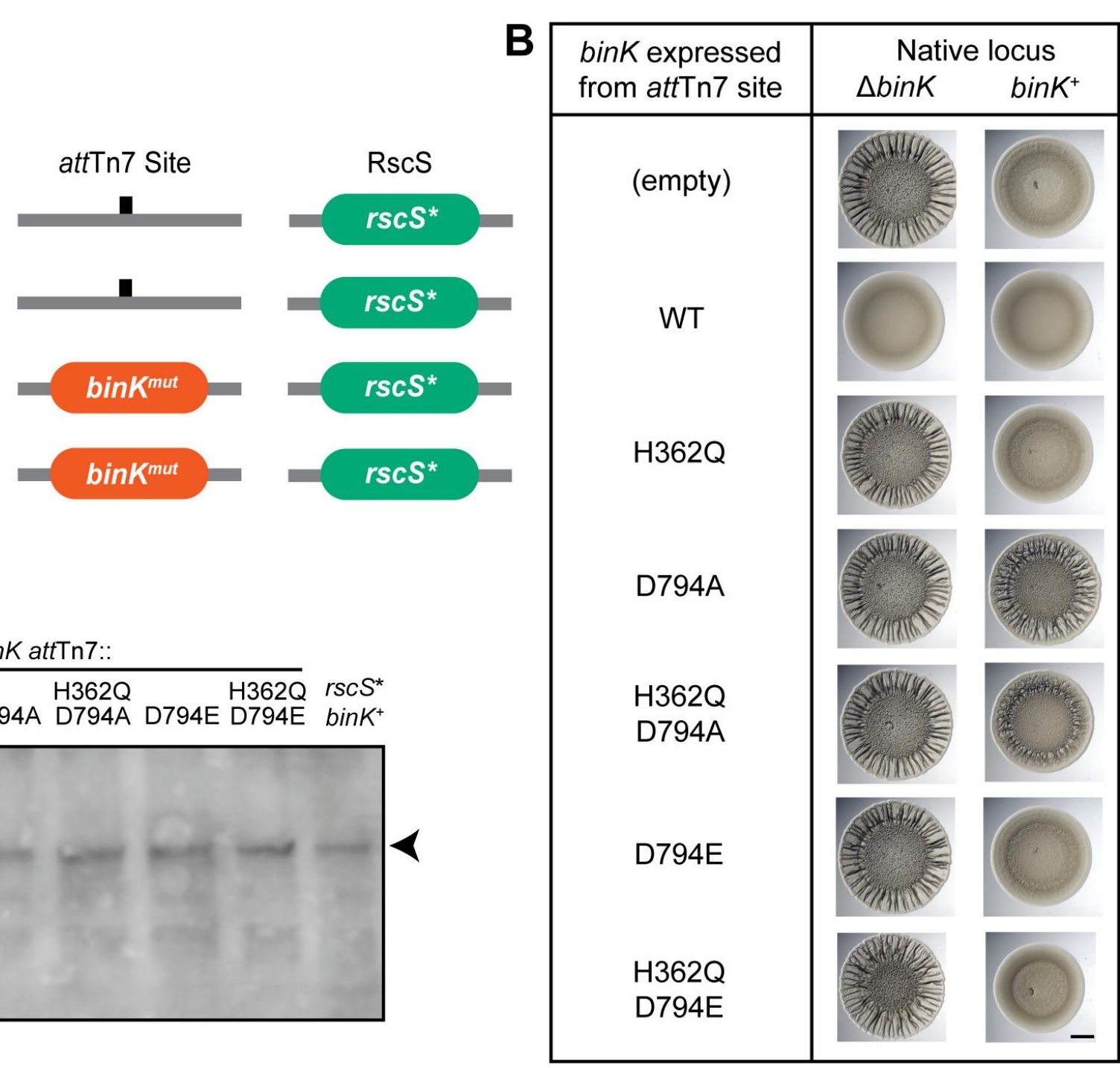


A

Luminesence

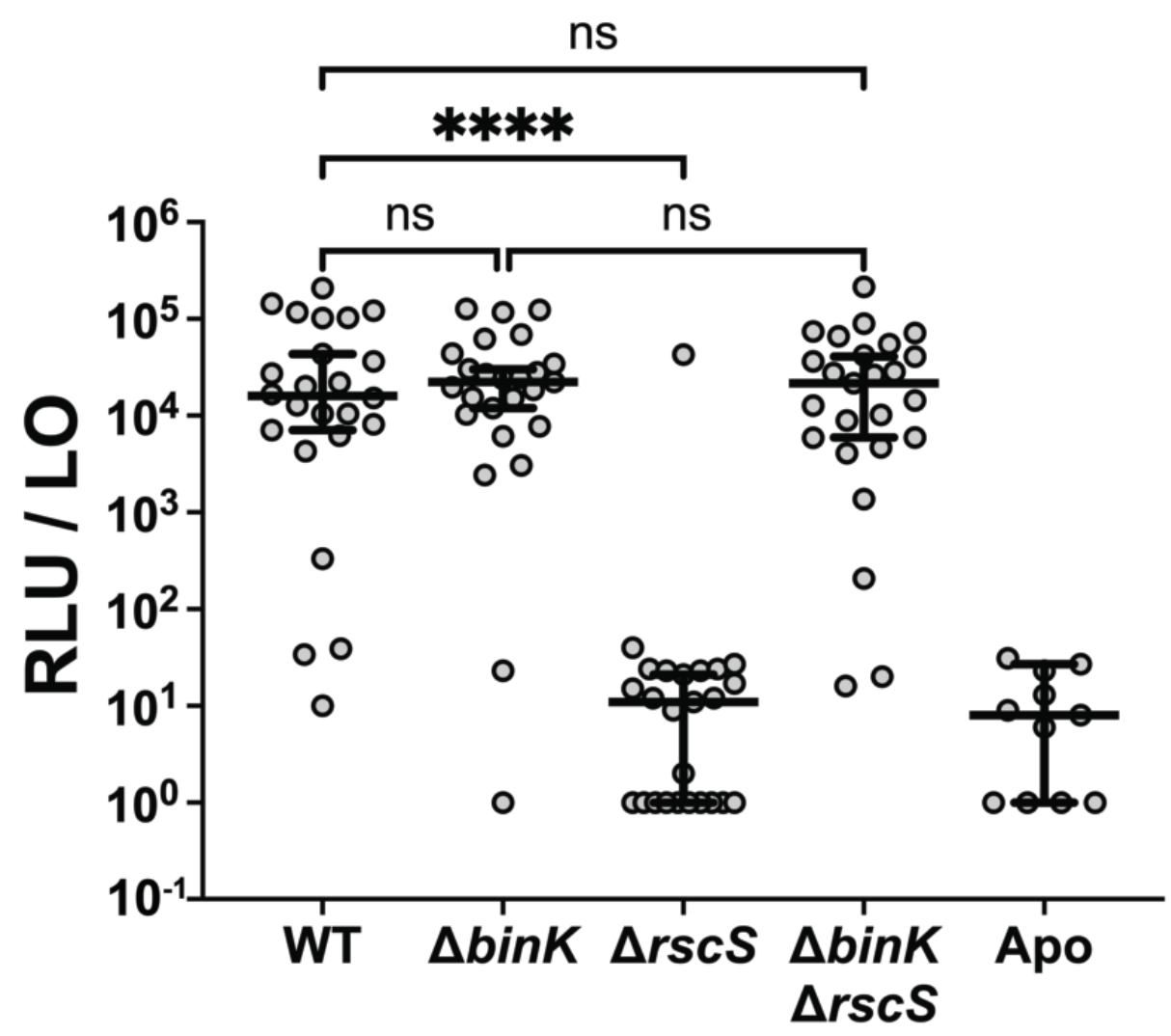

B

CFU

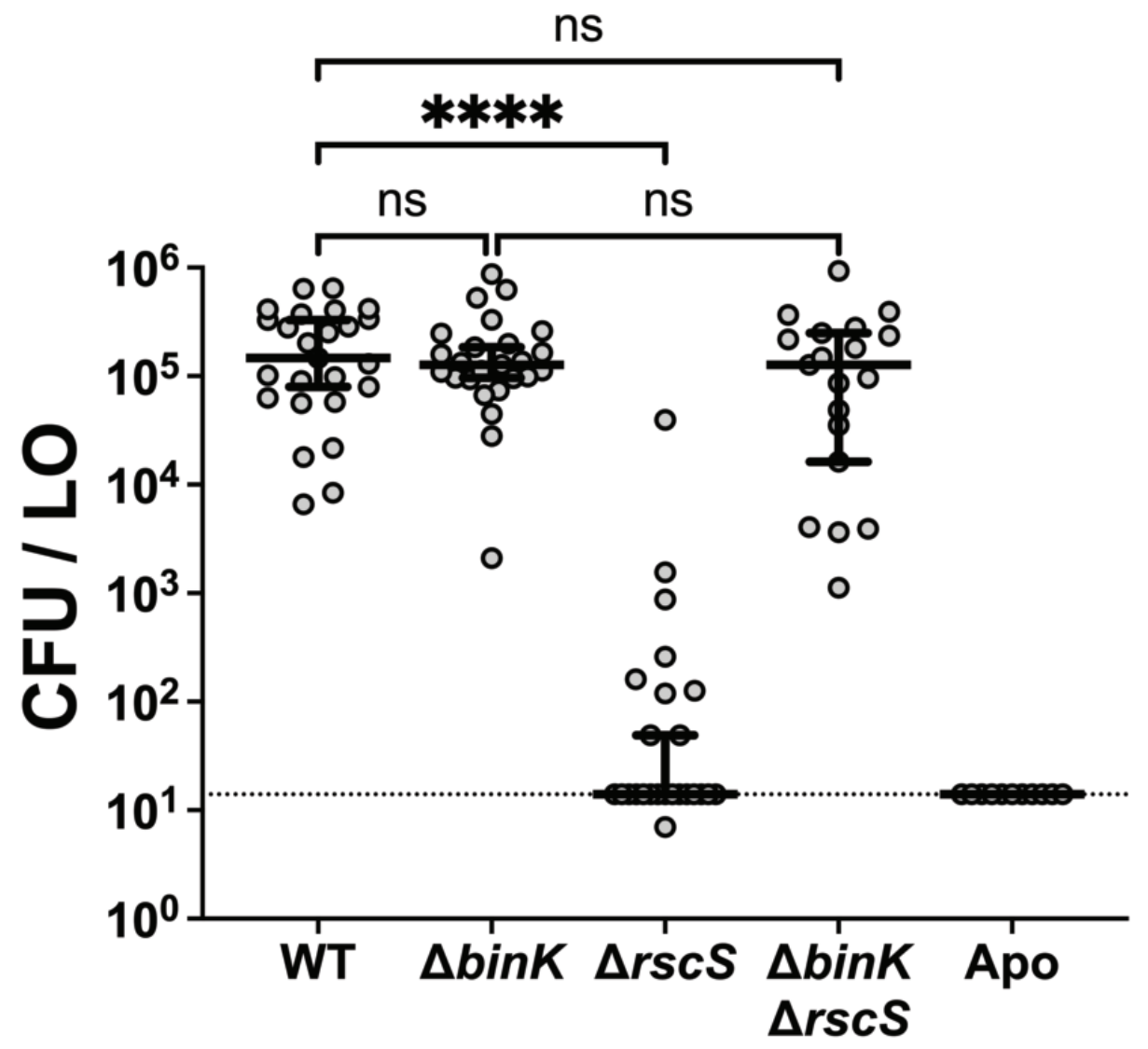




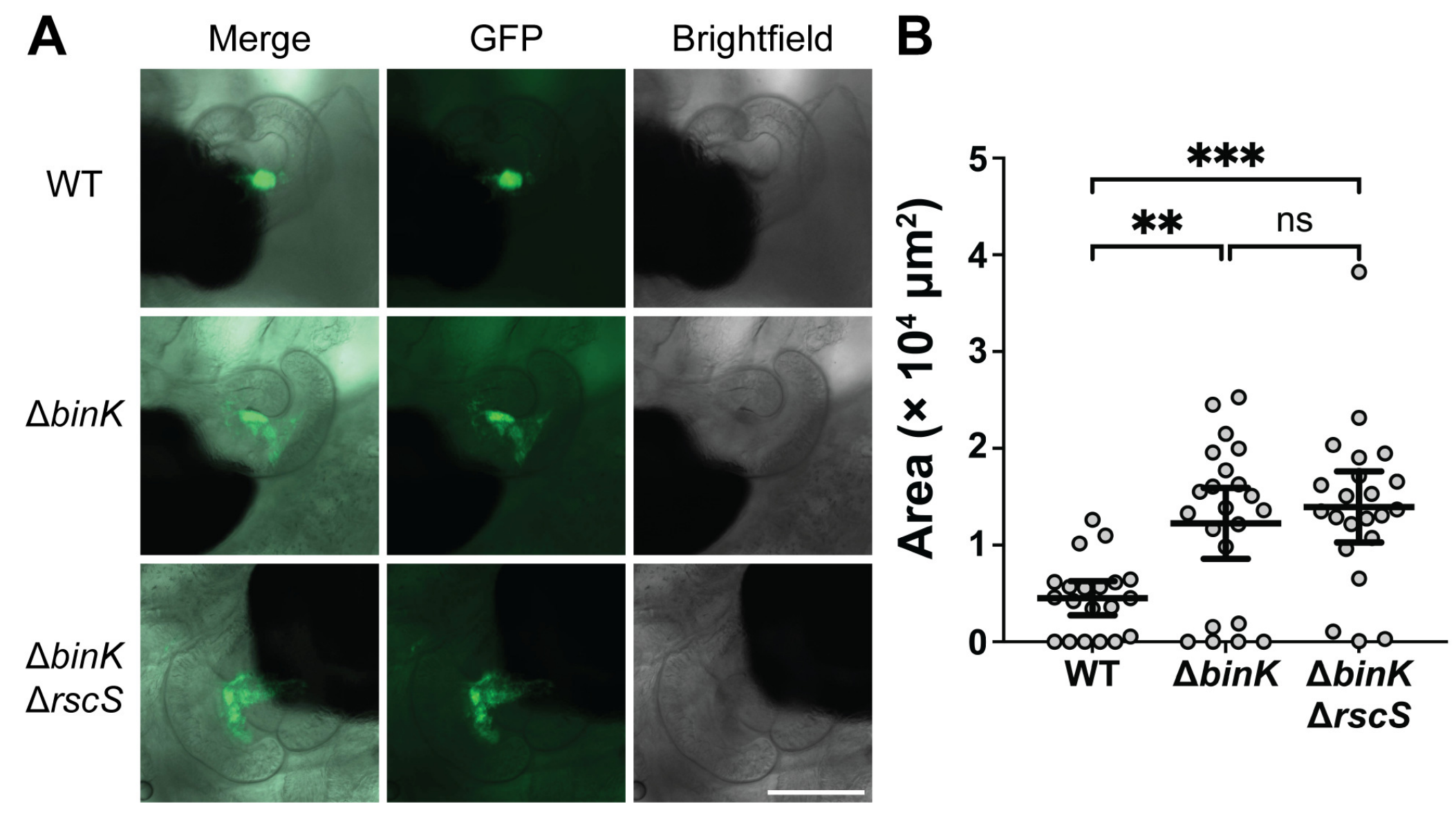


bioRxiv preprint doi: https://doi.org/10.1101/2021.03.29.437627; this version posted May 12, 2021. The copyright holder for this preprint (which was not certified by peer review) is the author/funder, who has granted bioRxiv a license to display the preprint in perpetuity. It is made available under aCC-BY 4.0 International license.

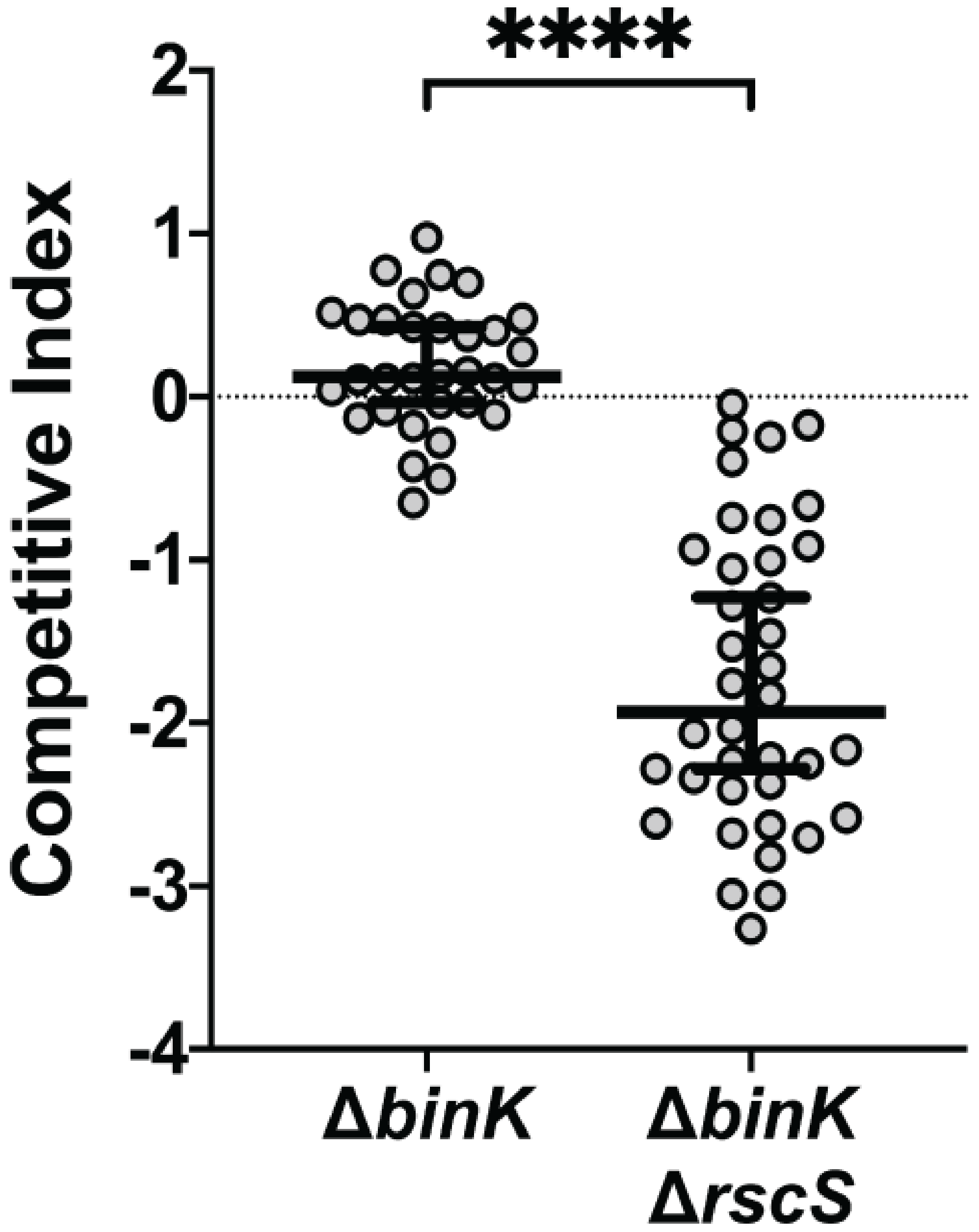


A

LBS-Calcium

B

LBS
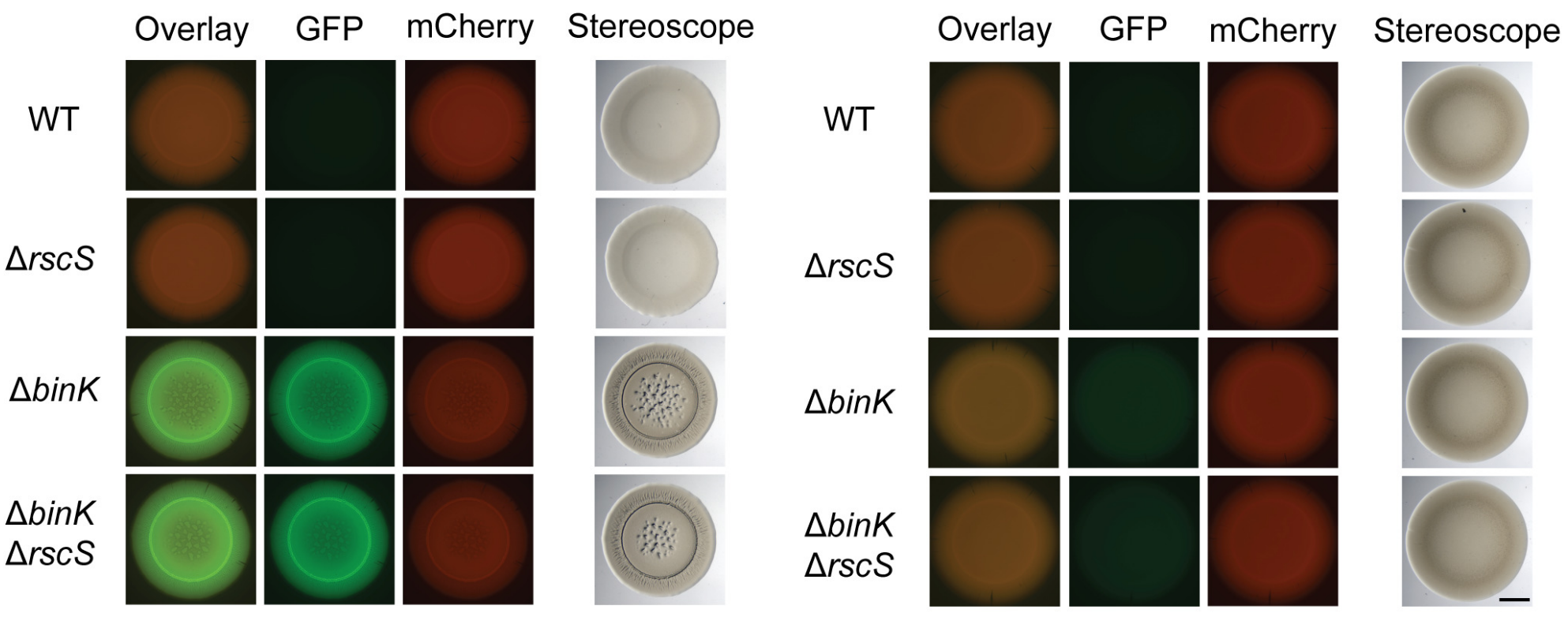

C

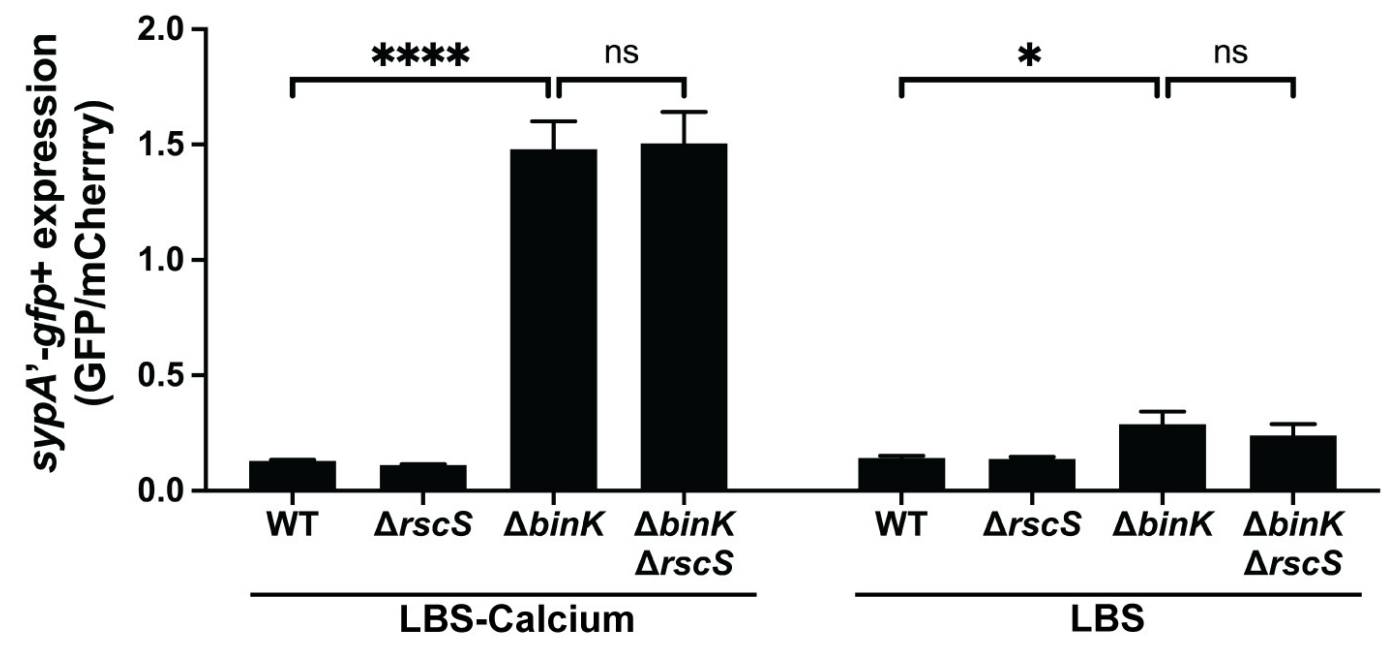


A

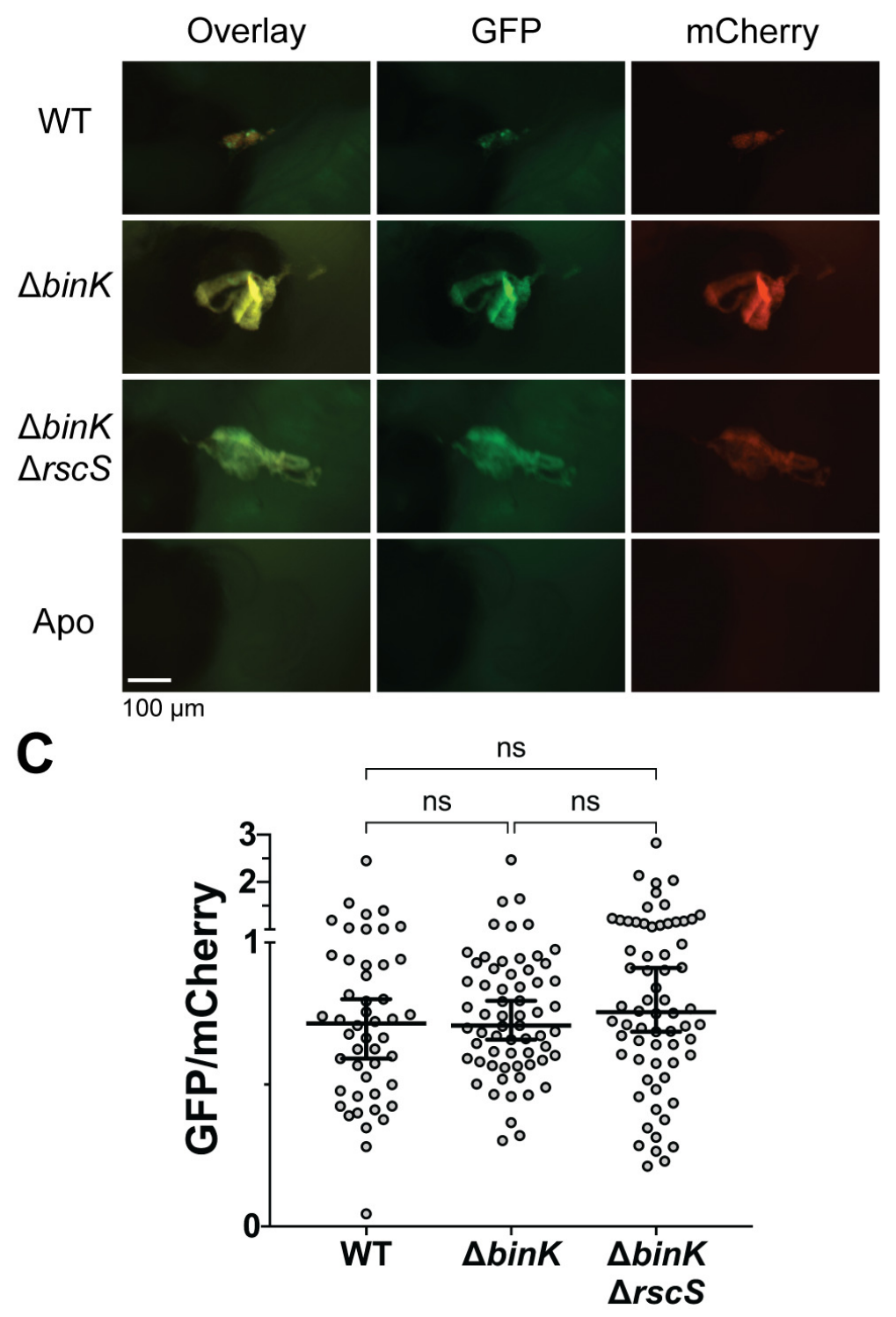

B

In the crypts at $\mathbf{4 8} \mathrm{hpi}$

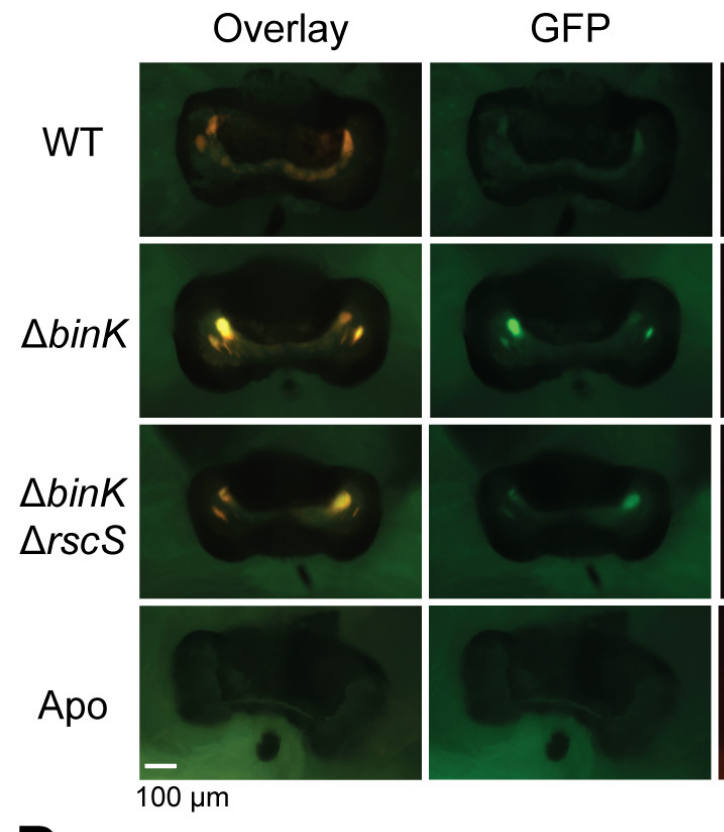

mCherry

D

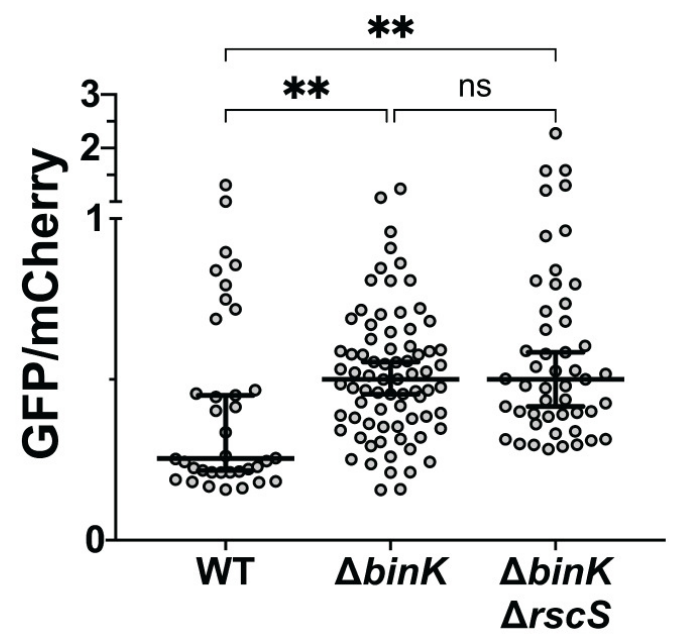

